
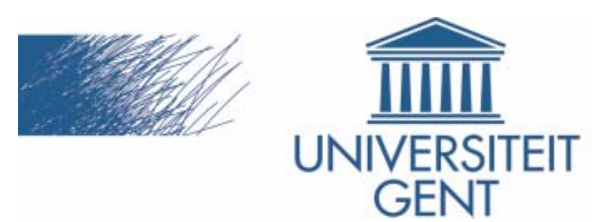

biblio.ugent.be

The UGent Institutional Repository is the electronic archiving and dissemination platform for all UGent research publications. Ghent University has implemented a mandate stipulating that all academic publications of UGent researchers should be deposited and archived in this repository. Except for items where current copyright restrictions apply, these papers are available in Open Access.

This item is the archived peer-reviewed author-version of:

Thermo-hydraulic study of a single row heat exchanger consisting of metal foam covered round tubes

C. T'Joen, P. De Jaeger, H. Huisseune, S. Van Herzeele, N. Vorst, M. De Paepe

International Journal of Heat and Mass Transfer, 53, 3262-3274, 2010

To refer to or to cite this work, please use the citation to the published version:

C. T'Joen, P. De Jaeger, H. Huisseune, S. Van Herzeele, N. Vorst, M. De Paepe (2010).

Thermo-hydraulic study of a single row heat exchanger consisting of metal foam covered round tubes. International Journal of Heat and Mass Transfer 53 3262-3274.

doi:10.1016/j.ijheatmasstransfer.2010.02.055 


\title{
Thermo-hydraulic study of a single row heat exchanger consisting of metal foam covered round tubes
}

\author{
C. T'Joen ${ }^{* 1}$, P. De Jaeger ${ }^{2,3}$, H. Huisseune ${ }^{3}$, S. Van Herzeele ${ }^{3}$, N. Vorst ${ }^{3}$ and M. De Paepe ${ }^{3}$ \\ ${ }^{1}$ Department of Radiation, Radionuclides and Reactors, Delft University of Technology \\ Mekelweg 15, 2629 JB Delft, The Netherlands \\ ${ }^{2}$ NV Bekaert SA, Bekaertstraat 2 - 8550 Zwevegem - Belgium \\ ${ }^{3}$ Department of Flow, Heat and Combustion Mechanics, Ghent University
}

Sint-Pietersnieuwstraat 41 - 9000 Gent - Belgium

\begin{abstract}
Open cell metal foam is a novel engineering material that offers an interesting combination of materials properties from a heat exchanger point of view such as a high specific surface area, tortuous flow paths for flow mixing and low weight. A new heat exchanger design with metal foams is studied in this work, aimed at low airside pressure drop. It consists of a single row of aluminum tubes covered with thin layers (4-8 $\mathrm{mm}$ ) of metal foam. Through wind tunnel testing the impact of various parameters on the thermo-hydraulic performance was considered, including the Reynolds number, the tube spacing, the foam height and the type of foam. The results indicated that providing a good metallic bonding between the foam and the tubes can be achieved, metal foam covered tubes with a small tube spacing, small foam heights and made of foam with a high specific surface area potentially offer strong benefits at higher air velocities ( $>4 \mathrm{~m} / \mathrm{s}$ ) compared to helically finned tubes. The bonding was done by conductive epoxy glue and was found to have a strong impact on the final results, showing a strong need for a cost-effective and efficient brazing process to connect metal foams to the tube surfaces.
\end{abstract}

Keywords: metal foam, single row, heat exchanger

\section{Nomenclature}

a,b,c,d fitting coefficients, Eq. (10) - (11) [-]

A $\quad$ area $\left[\mathrm{m}^{2}\right]$

$\mathrm{A}_{\mathrm{c}} \quad$ minimal free flow area $\left[\mathrm{m}^{2}\right]$

\footnotetext{
* Corresponding author: E-mail: christophe.tjoen@ugent.be, Tel: +32 926433 55, Fax: +32 92643575
} 


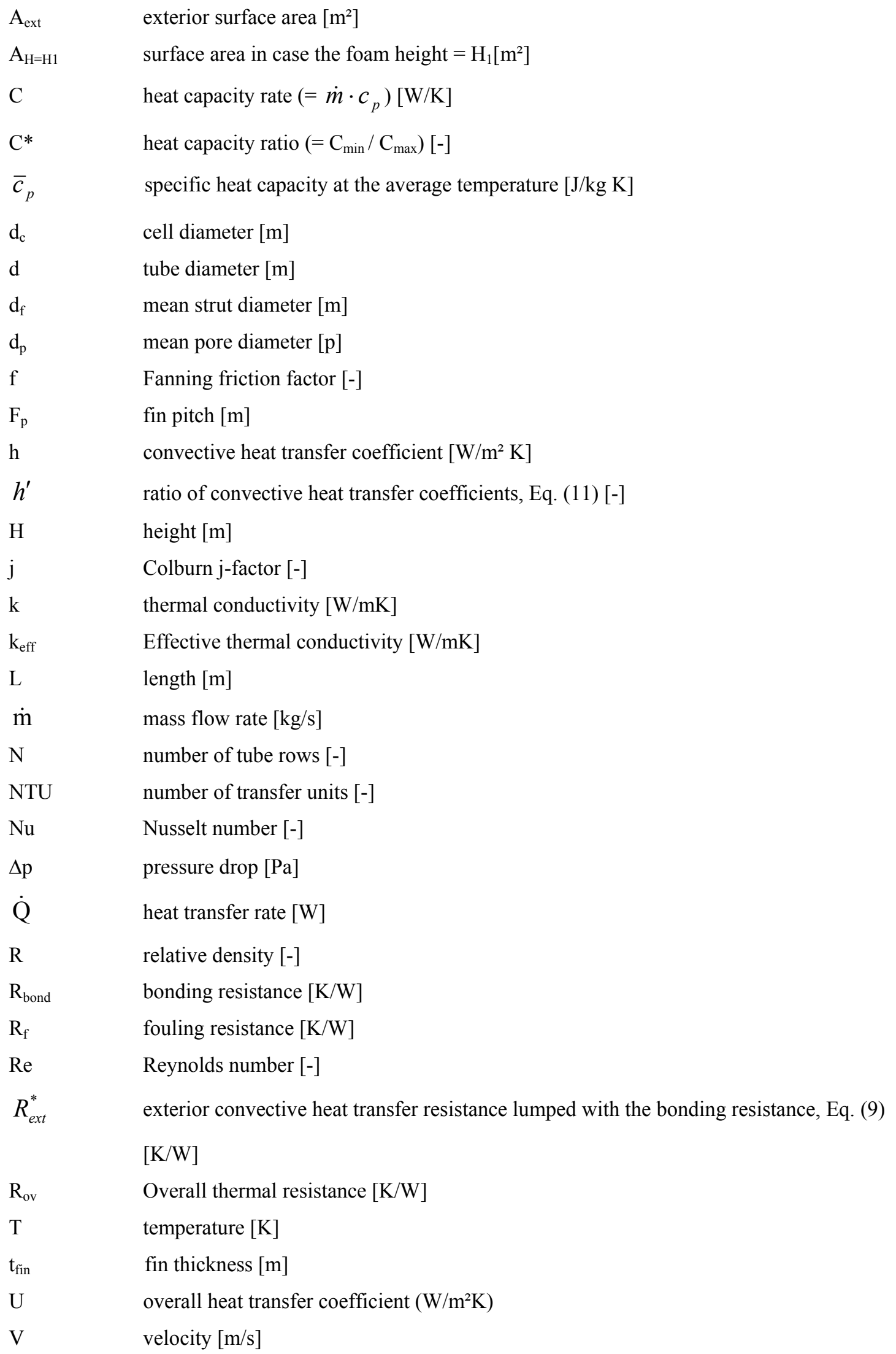




$$
\begin{array}{ll}
\mathrm{X}_{\mathrm{T}} & \text { transversal tube pitch [m] } \\
X_{l}^{*} & \text { dimensionless longitudinal tube pitch [-] } \\
X_{T}^{*} & \text { dimensionless transversal tube pitch, Eq. (1) [-] }
\end{array}
$$

\section{Greek symbols}

$\begin{array}{ll}\varepsilon & \text { porosity [-] } \\ \varepsilon_{\mathrm{NTU}} & \text { heat exchanger effectiven } \\ \eta_{\text {ext }} & \text { exterior surface efficiency } \\ \mu & \text { dynamic viscosity [Pa s] } \\ \rho & \text { density }\left[\mathrm{kg} / \mathrm{m}^{3}\right] \\ \text { Subscripts } & \\ \text { air } & \text { air } \\ \text { epoxy } & \text { related to the epoxy glue } \\ \text { ext } & \text { exterior (air side) } \\ \text { fin } & \text { fin } \\ \text { in } & \text { inlet } \\ \text { int } & \text { interior (water side) } \\ \mathrm{m} & \text { mean value } \\ \text { out } & \text { outlet } \\ \text { ref } & \text { reference material } \\ \mathrm{T} & \text { tube } \\ \mathrm{w} & \text { water }\end{array}$

\section{Introduction}

Heat transfer as an energy transfer process affects every facet of our day-to-day lives, ranging from the generation of power (electricity), to cooking and preserving food (refrigeration) and providing a suitable indoor climate (HVAC - air conditioning). Because of the huge variety in the nature of the processes involving heat transfer, heat exchangers can take on many different forms (a classification can be found in e.g. Shah and Sekulic [1]). Regardless of their form, the heat exchangers are very important to the overall efficiency of the energy transfer process, and to the cost and size of the system. A very typical application is the exchange of heat between a liquid and a gas (e.g. air conditioning, energy recovery from air streams...). Two commonly used heat exchanger designs for this application are the fin-and-tube and the plate-fin design. These heat exchangers are most often constructed using copper, aluminum or steel. A large amount of technical literature can be found on how to enhance the heat transfer rate or performance of 
these conventional designs by e.g. using corrugated or interrupted fins or vortex generators [2-3]. However, the operating limits of metallic heat exchangers in some applications have created the need to develop alternative designs using other materials. One of the materials that have been drawing a lot of attention over the past decades is open cell metal foam.

\section{Literature Survey}

\subsection{Metal foam}

Metal foam or cellular metal can be categorized as (i) an open- or closed-cell structure; or as (ii) a stochastic or ordered/periodic structure. Open-cell foam consists of cells which all are interconnected ('without walls') allowing a fluid to pass through; while in closed-cell foam the cells form individual enclosures within the material. Periodic cellular metal structures are clearly very different from the stochastic orientation of foams. Examples include materials made from stacked metal textiles and microtruss concepts (Wadley [4]). Compared to ordinary metals, the most prominent feature of open cell metal foams is the existence of many voids within the material. These foams are known to have many interesting combinations of physical and mechanical properties (Tuchinski [5] - Liu and Liang [6]), including:

1) Low weight (composed of about $90 \%$ of air);

2) High to very high specific surface area $\left(500\right.$ to over $\left.10.000 \mathrm{~m}^{2} / \mathrm{m}^{3}\right)$;

3) High gas permeability combined with high thermal conductivity;

4) Resistance to thermal shock, wear, high temperature, humidity, and thermal cycling;

5) High strength and toughness, suitable for high-pressure conditions;

6) Good impact energy absorption;

7) Easy control over material morphology (pore size and distribution);

8) Machinability and weldability, allowing the formation of complex parts;

9) Excellent noise attenuation;

10) Excellent fluid mixing due to tortuous flow path.

Some of these properties clearly imply a potential to develop compact heat exchangers.

Lu et al. [7] provide a comparison based on numerical and experimental data of different methods which can be applied to cool a hot wall of a channel. The results are summarized in Fig. 1a and b. A comparison of these two plots shows the counteracting influences of the topology on the Nusselt number and friction factor. This implies that the selection of a specific topology depends on the application. In most cases, this choice is dictated by a maximum allowable temperature in the metal and/or the fluid, which is subjected to either a specified pressure drop or pumping power. Different scenarios can be considered. When there is no constraint on either the pressure drop or the pumping power, and the goal is to maximize the heat transferred per unit temperature difference, $\mathrm{Nu}$ must be as large as possible. Then, Fig. 1a immediately reveals the best technologies, which include foams, prismatic cores and trusses. If the heat transferred per 
unit temperature difference and pressure drop needs to be maximized, then $\frac{N u}{f \cdot \mathrm{Re}^{2}}$ must be as large as possible (see Lu et al. [7] for the derivation). The best candidates are then empty channels with a laminar flow, louvered fins and corrugated ducts. However, if the structure must also support bending loads, all of these systems are excluded, because of their low core shear strength and stiffness. In that case, truss and prismatic cores and metal textiles outperform all other options. These results indicate the potential benefit of metal foams but also immediately indicate a strong disadvantage, the high frictional pressure drop.

Heat conduction in porous matrices has been studied in detail by many researchers and has been summarized in a number of extensive reviews (Kaviany [8], Alazmi and Vafai [9]). In the past different models have been proposed for the effective thermal conductivity. Noteworthy are the models of Calmidi and Mahajan [10], Boomsma and Poulikakos [11] and Singh and Kasana [12]. For high porosity metal foams Calmidi and Mahajan [10] presented a one dimensional heat conduction model in which the porous medium is modeled as a two dimensional array of hexagonal cells. Boomsma and Poulikakos [11] proposed a three dimensional metal foam model consisting of tetrakaidecahedron cells with cubic nodes at the intersection of two fibers. Both these models use a geometric parameter that is determined from experimental data. Singh and Kasana [12] recently presented a simple semi-empirical model for $\mathrm{k}_{\text {eff }}$ of metal foams showing good agreement with experimental data. Increasing the foam density (e.g. through compression) will result in a larger value of $\mathrm{k}_{\text {eff. }}$. On the other hand, convective heat transfer through a metal foam is enhanced by thermal dispersion (intra-cell mixing), and dispersive effects increase with permeability (see Angirasa [13]). Thus, foam with a high relative density has a high thermal conductivity, but foam which is more "open" is likely to perform better in convective heat transfer. This presents an interesting trade-off for designers.

Metal foams can be manufactured through different processes, including investment casting, use of filler materials, direct gas injection or blowing agents as listed by Banhart [14]. The cells are usually polyhedrons with 12-14 faces and in which each face has a pentagonal or hexagonal shape. The porosity of a metal foam sample can be estimated by using the weight of a given volume of the material and the density of the base material. Apart from the porosity there are two other parameters which are used to quantify the foam. These are the average pore diameter $d_{p}$ (the average diameter of the best fitting sphere within a cell), and the strut diameter $d_{f}$. The pore diameter is often specified by counting the number of pores over a given length: 'ppi' or pores per inch is a nominal value specified by manufacturers. The typical area density of 20 ppi foam with a porosity of 0.85 is $2000 \mathrm{~m}^{2} / \mathrm{m}^{3}$. Typical values of ppi range in between 5 and 100 for uncompressed foams. The strut diameter can be determined by measuring cross sections in a sample using an optical microscope or scanning electron microscope (SEM). Different models have been proposed to link the macroscopic porosity to the microscopic properties $\left(d_{p}\right.$ and $\left.d_{f}\right)$ based on a geometric model of the cell shape. These were recently summarized by Mahjoob and Vafai [15]. The open 
cell metal foam used in this study was produced by means of investment casting. For this paper, metal foam was characterized by means of X-ray computed tomography. The highest spatial resolution of the system, depending on the sample size is $2 \mu \mathrm{m}$. The reported results are based on a spatial resolution of $40 \mu \mathrm{m}$ to be able to scan a representative foam volume. Further details on the apparatus and data processing can be found at Cnudde [16], Masschaele [17] and Vlassenbroeck [18]. The scan results are listed in Table 1. Porosity is strongly dependent on compression. As pre-treatment of the foam (grinding, reshaping...) can cause local compression, it is important to clearly identify what is measured. In this study porosity of machined slices were measured, before shaping around the tubes, as this operation inherently compresses the foam locally, which consequently is not taken in account in the porosity measurement. The porosity values reported thus show the average foam value before being attached to the tube. Other geometrical parameters of the different foam species are listed (pore diameter $d_{p}$, cell diameter $d_{c}$ and equivalent strut diameter $\mathrm{d}_{\mathrm{f}}$ ). As explained earlier, strut diameter tends to vary along the strut length. For this reason, this parameter is determined in the middle of the strut. Equivalent strut diameter is the diameter of a round slice with the same surface area as the strut cross section. The final parameter is the specific surface area (SA). It was found that scan resolution has a significant influence on the obtained result. A smaller sample of foam 1 was scanned with $8.5 \mu \mathrm{m}$ resolution instead of $40 \mu \mathrm{m}$. SA changed from $720 \mathrm{~m}^{2} / \mathrm{m}^{3}$ to $860 \mathrm{~m}^{2} / \mathrm{m}^{3}$. This difference can be explained by looking at the amount of solid material (grey value) in a voxel at the edges of the struts. If this amount is below a certain threshold, it is not taken into account. It can be easily understood that this will happen more often in a $40 \mu \mathrm{m}$ resolution then when $8.5 \mu \mathrm{m}$ resolution is used. All reported values were obtained with $40 \mu \mathrm{m}$ resolution.

\subsection{Metal foam heat exchangers}

As stated above, metal foams present a number of interesting material properties for the development of compact heat exchangers, specifically: a (very) high surface to volume ratio, strong mixing capability, low weight and high toughness (compared to the current state of the art: louvered fins). Quite a large number of technical papers have already been presented in open literature reporting on the development of a heat exchanger using metal foams. In the subsequent literature survey some of the previously published results will be listed, focusing on the application of (metal) foam to enhance the heat transfer rate.

Boomsma et al. [19] used compressed aluminum foam to manufacture heat sinks. The foam was brazed onto a heat spreader plate and filled the entire channel height. Water was used as a fluid and circulated through the metal foam. They studied the impact of varying compression on the thermo-hydraulics and found that increasing the compression rate resulted in a both a larger pressure drop and heat transfer. To evaluate the heat exchanger performance they compared the required pumping power to the thermal resistance and found that using the metal foam heat exchangers results in a reduction of the thermal resistance $\mathrm{R}_{\text {th }}$ by up to $50 \%$ for the same conditions. A comparison to 3 reference cases (commercially 
available plate heat exchangers) showed that the metal foams performed better. Boomsma et al. [19] also showed that the increased heat transfer comes at a large cost; there is a strong increase in pressure drop. They reported that part of the increased pressure drop was due to brazing imperfections. As the foam is compressed further and the cells become smaller, some of the cells near the plate would get filled entirely with brazing material. Tadrist et al. [20] studied glycol/water-air cross flow heat exchangers consisting of flat tubes with aluminum foam brazed in between. Three types of foam (10, 20, and 40 ppi) were used in these exchanger prototypes. The tubes were also spaced at two different distances ( $2.5 \mathrm{~mm}$ and $5.3 \mathrm{~mm})$. They reported no noticeable differences in Colburn factor between the various designs. Unfortunately no pressure drop data or a comparison with a conventional fin-and-tube design was presented. Kim et al. [21] experimentally studied the heat transfer and pressure drop of metal foam brazed in between two flat tubes at constant temperature (representing a small section of a water-air heat exchanger) and compared the data to a standard louvered fin design. Six types of foam were considered with varying porosity $(0.89-0.96)$ and varying ppi (10 - 40). Compared to louvered fins the porous fins resulted in much higher friction factors at high Reynolds numbers. But due to the high heat transfer rate of the porous fins, the louvered fin only has a slightly higher volume goodness value (volume goodness is a measure for the compactness of a heat exchanger). The volume goodness results indicated that porous fins with low permeability and low porosity are preferable with regards to the compactness of porous fin heat exchangers. Hsieh et al. [22] experimentally determined heat transfer correlations for 6 types of aluminum foam heat sinks (pore density: $10-40$ ppi, porosity: $0.87-0.96$ ) and found that increasing the porosity and the pore density results in a higher Nusselt number. The studied configuration is similar to a processor cooling heat sink with a fan mounted on top blowing air through the sink. All of the air is forced through the foam. Shih et al. [23] further studied the impact of the height of the heat sink and found that an optimal height exists related to the foam porosity: reducing the height of the heat sink allows more of the air to reach the base surface resulting in a larger heat transfer rate. Below a certain height, further reduction removes exterior surface area and thus reduces the performance.

In the heat sink papers mentioned above, the channel was completely filled with metal foam or the flow was forced entirely through the foam. As expected, this results in high frictional losses. In a more realistic case, the heat sink will be placed in an open channel and air is allowed to bypass. Kim et al. [24] investigated the thermal performance of aluminum foam heat sinks for forced air-cooling of electronics. Test specimens of aluminum foam (porosity: 0.92 , pore density: $10,20,40$ ) heat sink were made by brazing a block of foam to a base plate. A thin base plate was used to reduce the influence of the conductive thermal resistance through the base plate on the overall thermal resistance. As a reference, a conventional heat sink with parallel plate fins was manufactured with the same height (half of the wind tunnel height). The results showed that compared to the plate fin heat sinks, the aluminum foam heat sinks were able to reduce the thermal resistance by up to $28 \%$ for a constant air inlet velocity. The pore density has a strong impact on the results as the heat sink with 10 ppi foam obtains Nu values that are $16-27 \%$ higher than those 
of the heat sink with 40 ppi foam. This is of course due to the reduced flow resistance of the more open foam which reduces the bypass. Another important thing to note is that the weight of the aluminum foam heat sinks was only $25 \%$ of that of the plate fin heat sink, again stressing the advantage of these materials. Bhattacharya and Mahajan [25-26] developed a new heat sink design, a finned metal foam heat exchanger. It consists of a number of parallel plate fins with metal foam joined in between. When used in natural convection mode, Bhattacharya and Mahajan [26] found that this design provided an increase in heat transfer compared to an optimized plate fin heat sink. The 5 ppi foam results in an increase of the heat transfer coefficient ranging from $65 \%$ to $24 \%$ depending on the temperature difference between the base and the inlet air $\left(10^{\circ} \mathrm{C}\right.$ and $50^{\circ} \mathrm{C}$ respectively). In forced convection [25] the finned metal foam heat sinks also outperform the parallel plate heat sinks by a factor of 1.5 to 2 . More dense foams provided less benefit due to increased flow resistance in both natural and forced convection. It should be pointed out that the finned metal foam heat sinks were not optimized so further performance improvement is realistic, and more importantly, the metal foams were joined to the plate fin surface using epoxy glue and were not brazed. As shown by other researchers, e.g. Bastawros and Evans [27], this bonding method can result in a poor heat transfer of the foam configuration.

Klett et al. [28] and Gallego and Klett [29] report on using graphite foam for heat exchangers and heat sinks respectively. This material has a higher thermal conductivity than aluminum foam and a lower porosity, consisting of smaller pores. Klett et al. [28] built a foam heat exchanger by inserting tubes into a graphite foam block. The target application is the cooling of a high power race engine ( $800 \mathrm{hp}$ ). They reported very high heat transfer coefficients ranging between 5000 and $16000 \mathrm{~W} / \mathrm{m}^{2} \mathrm{~K}$, but with a similarly extreme pressure drop of $5.4 \mathrm{kPa} / \mathrm{cm}$. In order to reduce the pressure drop, the design was modified to incorporate large open sections and locally thinner sections of foam. The entire structure (fins and through holes) was machined from a foam block and the aluminum flat tubes were press-fit into pre made openings. The resulting pressure drop was only $0.03 \mathrm{kPa} / \mathrm{cm}$, a significant reduction. Gallego and Klett [29] compared an aluminum and carbon foam heat sink. They found that the carbon foam heat sinks resulted in a higher heat transfer coefficient (for a massive foam block $(5 \times 5 \times 3.8 \mathrm{~cm}) 2600 \mathrm{~W} / \mathrm{m}^{2} \mathrm{~K}$ compared to 250 $\mathrm{W} / \mathrm{m}^{2} \mathrm{~K}$ for the aluminum foam) but also a large pressure drop. In order to reduce the pressure drop, Gallego and Klett [29] turned to classic designs and by drilling holes into the foam block (parallel and perpendicular to the flow), making pin fins or even a corrugated fin design they managed to significantly reduce the pressure drop and for some designs even increase the heat transfer coefficient. Similar findings were reported by Leong et al. [30] who used graphite foam $(\varepsilon=0.75)$ to build heat sinks and who compared four different designs: a massive block, and 3 fin like designs, having a baffled or a zigzag structure. The individual fins in these designs measured between 2 and $3 \mathrm{~mm}$ and could be machined fairly easily. The results showed that the massive block provides a larger heat transfer rate than the finned designs but that the finned designs result in a significant reduction of the pressure loss. In a related numerical study, Sumithra Raju and Narasimham [31] reported on the heat transfer and pressure drop of an inline tube 
bundle (5 rows) with porous fins. The width of the porous fin was varied from 0 to half of the transversal tube pitch. It was found that by using a porous fin ( $\varepsilon: 0.58)$ with a width of $0.45 \mathrm{X}_{\mathrm{T}}$ the Nu number was reduced by $50 \%$ compared to a channel filled completely with foam, but the pressure drop was reduced from $22.5 \mathrm{kPa} / \mathrm{m}$ to $35 \mathrm{~Pa} / \mathrm{m}$, showing an enormous reduction.

Straatman et al. [32] went one step further, and studied using thin layers of carbon foam ( $\varepsilon$ varying between 0.67 and 0.84 ) on top of a surface as a 'roughness' element to enhance heat transfer. They brazed a thin section of carbon foam onto a heater plate and then subjected this heat sink to a parallel flow $(3-10 \mathrm{~m} / \mathrm{s})$. The initial layer thickness was $10 \mathrm{~mm}$. By milling down the surface and measuring the heat transfer enhancement for the different foam heights, they were able to show that the air only penetrates a few $\mathrm{mm}$ into the foam and that using more than $3 \mathrm{~mm}$ foam does not provide a large advantage. This means that the penetration depth of the air is only 3-5 pore diameters. This depth of course is a strong function of the incidence of the air flow and will be higher for impinging flow. They also reported that the enhancement decreases as the Reynolds number increases, relating this behaviour to the near-surface activity. For a parallel flow, the air is not driven into the foam, but the roughness of the surface will produce disturbances and near-surface eddies. These eddies in turn generate pressure gradients, forcing some of the flow to pass through the foam, exposing it to the large internal surface area and enhancing the heat transfer rate. At low air speeds these eddies have a low momentum, but the amount of air passing through the foam is 'significant'. At high air speeds, the eddies become very energetic, but only a small amount of air (compared to the external flow) passes through the foam. This results in a higher enhancement at low Reynolds numbers. Jamin and Mohamad [33] compared different methods of heat transfer enhancement using carbon foam $(\varepsilon=0.61)$ for a vertical tube $(15.9 \mathrm{~mm} \mathrm{OD})$. They considered a full sleeve surrounding the tube of varying thickness $(3-5 \mathrm{~mm}), 5 \mathrm{~mm}$ wide carbon foam fins (donuts surrounding the tube with a fin pitch of $5.5 \mathrm{~mm}$ and a height of 3 or $5 \mathrm{~mm}$ ) and aluminum fins ( $38 \mathrm{~mm} \mathrm{OD}, 0.38 \mathrm{~mm}$ thickness and a fin pitch of $2.52 \mathrm{~mm}$ ). The carbon foam was press-fit onto the tube using conductive paste to improve thermal contact. Their results indicated that the largest heat transfer enhancement was obtained by using the aluminum fins ( $\mathrm{Nu} 9$ times larger than that of a bare tube), followed by the large carbon foams fins $(\mathrm{Nu}$ 3.05 times than that of a bare tube). The full foam sleeve only resulted in an increase of 1.4. The full sleeve also resulted in the largest pressure drop (even higher than the aluminum fins which have a much larger OD). Jamin and Mohamad [33] however noted that if the Nu number ratio is compared to the surface ratio for the different cases, the carbon foam fins (2.65 surface ratio) provide more gain than the aluminum fins (surface ratio of 13.7). However, to define the surface ratio, they only considered the peripheral surface while some of the flow will enter the foam. The results do agree with the findings of Straatman et al. [32], showing that thick porous layers will act as a blunt object, without much flow passing through them.

Ghosh [34] recently provided an overview of past experimental and numerical (modeling) work done on open-cell metal foams. Using a cubic unit-cell model for the foam, correlations were derived for both the 
Colburn and friction factor. To evaluate the performance of metal foam as a heat exchanger surface the area goodness (the ratio of $\mathrm{j} / \mathrm{f}$ ) was used. A high area goodness value indicates a surface that results in heat exchangers with a smaller free flow area, and thus lower frontal area. Ghosh [34] compared the metal foam to wavy and offset strip fins, using data from Kays and London [35]. At low air velocities (up to 3 or $7 \mathrm{~m} / \mathrm{s}$ depending on the nature of the foam) the metal foams result in higher area goodness than the fins. The trend is also very different; the area goodness of metal foams drops off sharply as the velocity increases, while that of the fins slowly increases. Ghosh [34] attributes this to the strong increase in form drag as the velocity increases.

The presented results clearly show that using (metal) foam can provide large benefits to heat exchangers. So far the main success stories were heat sinks operating in both natural and forced convection. The application of foam directly into fin-and-tube designs has proved to be more challenging due to the large pressure drop on the air side. As a result, alternative designs are needed, in which the material properties are used more to their potential. In this regard, the work of Straatman et al. [32] provides an interesting idea, namely to use thin layers of foam material on tube surfaces to act as a heat transfer enhancer without much increase in pressure drop. This idea will be studied further here experimentally, but where Straatman et al. [32] used the low porosity carbon foam, very high porosity aluminum foams (see Table 1) will be applied in this study. Thin layers of aluminum foam (4-8 $\mathrm{mm}$ ) were connected to round $12 \mathrm{~mm}$ OD aluminum tubes, and these tubes were used to make single row heat exchanger. The impact of different foam porosity, foam height and the tube spacing were studied.

\section{Experimental set-up and procedure}

The test rig consists of an open air wind tunnel and a closed water cycle (see Fig. 2). This test setup and the measurement procedures were previously validated extensively (T'Joen et al. [36]-[37]). Measurements are performed on both sides of the heat exchanger. A radial fan sucks (1) air through a calibrated nozzle ( $2 \%$ uncertainty - ISO5167) (2). To determine the air mass flow rate the pressure drop over the nozzle is measured using a differential pressure transducer ( $\pm 1 \mathrm{~Pa}$ accuracy). The fan is driven by a frequency controller which allows setting an air mass flow rate between 0.1 and $1.1 \mathrm{~kg} / \mathrm{s}$ (corresponding with a velocity range from 0.7 to $7.4 \mathrm{~m} / \mathrm{s}$ at the inlet of the test section). After the diffuser (3), settling chamber (4) (with honeycomb (cell size 1/2 inch - 4 inch long) (5) and screen flow straightener (6)) and sinusoidal contraction section (7), a uniform air flow enters the test section (8). To avoid flow separation, the diffuser angle is reduced using baffles (9). The flow uniformity at the inlet of the test section was illustrated by T'Joen et al. [37] using a heated sphere anemometer and a bladed rotor measuring device. Hotwire measurements performed at the start of this measuring campaign confirmed the uniform inlet flow conditions. A single row array of metal foam covered tubes (10) was placed in the test section (8), which has a cross sectional area of $485 \times 255 \mathrm{~mm}$. The metal foam covered tubes were manufactured by first 
cutting a rectangular section of metal foam with the correct dimensions which was then folded tightly around the aluminum base tube $(0.01 \mathrm{~m} \mathrm{ID}, 0.012 \mathrm{~m} \mathrm{OD})$. The foam covered section had the same length as the wind tunnel width: $485 \mathrm{~mm}$. Prior to folding the foam, the tubes were covered with a thin layer of thermally conductive epoxy glue (Bondmaster ${ }^{\mathcal{O}}$ ESP-110). The metal foam was pressed hard into the epoxy to ensure good contact with the epoxy and a thin metal wire was wrapped around the assembly to ensure everything was fixed in place. The assembly was then placed in an oven to be cured at $150^{\circ} \mathrm{C}$ for $1 \mathrm{hr}$. Figure 3 shows a metal foam covered tube and a helically finned tube which was used for comparison. Depending on the transversal tube pitch $6,7,8$ or 9 tubes were positioned in the test section. The remaining gap between the tubes and the top and bottom of the wind tunnel is filled using a milled sheet of multiplex wood to $\mathrm{X}_{\mathrm{T}} / 2$ to prevent excessive flow bypass. The resulting non dimensional tube pitches are:

$$
X_{T}^{*}=\frac{X_{T}}{d_{e x t}}=2.38,2.68,3.06,3.57
$$

The closed water cycle consists of an electric boiler (11) with a power limit of $6 \mathrm{~kW}$, several valves (12) and a circulation pump (13). The inlet water temperature is controlled with a PID controller and is set to 63 ${ }^{\circ} \mathrm{C}$. The pump is driven by a frequency controlled motor, thus allowing for a flow rate to be set. The water mass flow rate is measured with a calibrated electromagnetic flow meter $(14, \pm 2 \%$ accuracy). To prevent damage to the heat exchanger by overpressure, pressure gauges monitor the overall pressure level in the system. The test section, the tubes and the distributors bringing the hot water to the heat exchanger are surrounded by a box filled with vermiculite grains to avoid heat losses to the environment during the measurements. The water flows through the heat exchanger in two passes ( 3 by 3,3 by 4,4 by 4 or 4 by 5 depending on the transversal tube pitch). The tubes at the top of the test section contain the hottest water. The metal foam tubes are connected to the collectors using flexible metal tubes. All temperatures were measured using calibrated $\mathrm{K}$ type thermocouples (indicated with T symbols in Fig. 2, $\pm 0.1 \mathrm{~K}$ ) and read with a Keithley 2700 Multimeter/Data Acquisition System ((15) in Fig. 2). Because of uniform inlet conditions, it was sufficient to insert only two thermocouples in the test section upstream the heat exchanger to measure the inlet air temperature. The averaged value was used in the calculations. Downstream of the heat exchanger, the temperature profile of the cross section was no longer uniform because the water travels in 2 passes. Exit air temperatures were simultaneously measured on twelve different locations: three rails with each 4 thermocouples were positioned in a cross section downstream the heat exchanger. The average of these 12 values was used as the air exit temperature. The water inlet and exit temperatures were measured with two thermocouples placed in the center of the respective distributors, as recommended by Rose [38]. The pressure drop over the heat exchanger and across the inlet nozzle was measured using a differential pressure transducer ( $\pm 0.5 \mathrm{~Pa}$ accuracy). The pressure drop measurements were performed without heating.

The measurements were performed under steady state conditions for different Reynolds numbers on the air side. The steady state regime was verified by monitoring the water temperature variation. Every $3.5 \mathrm{~s}$ all variables were recorded and once the variation of the exit water temperature was within $0.1{ }^{\circ} \mathrm{C}$ for the past 
100 records, steady state was assumed to be reached. From then on 100 records were recorded and these were used as the measured data. Twice the standard deviation of the 100 temperature measurements was used as uncertainty on these averaged temperatures, as suggested by Moffat [39]. In order to be able to indicate the quality of the measurements a thorough uncertainty analysis was performed according to Moffat [39]. The uncertainties on the calculated results were determined with the root-sum-square method, unless it is mentioned otherwise. The uncertainties on the thermodynamic properties of water and air are based on recommendations in open literature [40-41]. The air density was calculated using the ideal gas law. The thermodynamic properties of water were calculated based on the IAPWS IF-97 formulation [42].

\section{Data reduction}

The air and water mass flow rates and temperature measurements are used to determine the heat transfer rate on the water and air side (Eqs. (2) - (3)). $\mathrm{T}_{\text {air,in }}$ and $\mathrm{T}_{\text {air,out }}$ are the averaged air temperatures at the inlet and outlet of the heat exchanger. All substance properties (such as $\bar{c}_{p}$ ) are determined at the average temperature between inlet and outlet and the corresponding pressure. The difference between both heat transfer rates is smaller than 5\% for all measurements. The mean heat transfer rate $\dot{\mathrm{Q}}_{\mathrm{m}}$ (Eq. (4)) is used in the remainder of the calculations.

$$
\begin{aligned}
& \dot{Q}_{\text {air }}=\dot{m}_{a i r} \cdot \bar{c}_{p, a i r} \cdot\left(T_{\text {air }, \text { out }}-T_{\text {air }, \text { in }}\right) \\
& \dot{Q}_{w}=\dot{m}_{w} \cdot \bar{c}_{p, w} \cdot\left(T_{w, \text { in }}-T_{w, \text { out }}\right) \\
& \dot{Q}_{m}=\frac{\dot{Q}_{\text {air }}+\dot{Q}_{w}}{2}
\end{aligned}
$$

The effectiveness $\varepsilon_{\mathrm{NTU}}$ is determined using Eq. (5). $\mathrm{C}_{\min }$ represents the smallest capacitive flow rate of the two fluid streams $\left(\dot{m} \cdot c_{p}\right)$ and $\mathrm{C}^{*}$ the ratio of the smallest to the largest capacitive flow rate. The mixed mixed formulation (Eq. (6)) is used to determine the NTU values, as recommended by Shah and Sekulic [1] and this because there is only one tube row, and there are no closed flow channels on the air side. The overall heat transfer resistance (UA) $)^{-1}$ can then be determined through Eq. (7).

$$
\begin{gathered}
\varepsilon_{N T U}=\frac{\dot{Q}_{m}}{C_{\min } \cdot\left(T_{w, i n}-T_{a i r, i n}\right)} \\
\varepsilon=\left(\frac{1}{1-e^{-N T U}}+\frac{C^{*}}{1-e^{-N T U \cdot C^{*}}}-\frac{1}{N T U}\right)^{-1} \\
\frac{1}{U A}=\frac{1}{C_{\min } N T U}
\end{gathered}
$$


As is clear from Eq. (8), the overall heat transfer resistance (UA) ${ }^{-1}$ consists of convective heat transfer and fouling resistances on the air side, contact resistance $\left(\mathrm{R}_{\text {bond }}\right)$ between the foam and tube, conductive resistance through the tube wall and finally the fouling and convective resistance on the water side. Clean air and filtered water are used during the experiments resulting in negligible fouling. Initially in this study, the bonding resistance will be lumped together with the exterior convective resistance resulting in $R_{\text {ext }}^{*}$ (Eq. (9)). This value can be obtained from the experimental measurements by subtracting the conductive and interior convective resistance from the overall resistance. Later on, the impact of the bonding resistance will be studied in more detail. To determine the interior convective resistance, the Gnielinski correlation [43] was used. This correlation is applicable for transitional and turbulent tube flows

$\left(\operatorname{Re}_{w}=\frac{\rho_{w} \cdot d_{\text {int }} \cdot V_{\text {int }}}{\mu_{w}}>2300\right)$. However, Abraham et al. [44] found that the Gnielinski correlation is only supported by experimental data in the range $\mathrm{Re}_{\mathrm{w}}>3100$ and should not be used below that value. In the current study $\mathrm{Re}_{\mathrm{w}}$ varied between 3100 and 7500 during the measurements. An uncertainty of $\pm 10 \%$ on the calculated water side Nusselt number was taken into account in the uncertainty analysis. For the tested heat exchanger design, the thermal resistance on the water side contributed on average $20 \%$ to the overall heat transfer resistance. The maximum contribution was $34 \%$. Hence, the controlling heat transfer resistance is located on the air side.

$$
\begin{gathered}
\frac{1}{U A}=\frac{1}{\eta_{\text {ext }} \cdot h_{\text {ext }} \cdot A_{\text {ext }}}+R_{f, \text { ext }}+R_{\text {bond }}+\frac{\ln \left(\frac{d_{\text {ext }}}{d_{\text {int }}}\right)}{2 \pi \cdot k_{T} \cdot L_{T}}+R_{f, \text { int }}+\frac{1}{h_{\mathrm{int}} \cdot A_{\mathrm{int}}} \\
R_{\text {ext }}^{*}=\frac{1}{\eta_{\text {ext }} h_{\text {ext }} A_{\text {ext }}}+R_{\text {bond }}=\frac{1}{U A}-\frac{\ln \left(\frac{d_{\text {ext }}}{d_{\text {int }}}\right)}{2 \pi \cdot k_{T} \cdot L_{T}}-R_{\mathrm{int}}
\end{gathered}
$$

When reporting on the thermo-hydraulic characteristics of a heat exchanger it is custom to use nondimensional numbers. The Nusselt number or Colburn $\mathrm{j}$-factor are commonly used to report on the heat transfer coefficient and the Fanning friction factor is used for the pressure drop. To evaluate these numbers the exterior surface area $A_{\text {ext }}$ must be known. For conventional fin designs, this value can be determined quite easily based on the geometry. But for metal foams, with their highly tortuous flow paths and cell structure, this is clearly not the case. Some authors combined a simplified model of the geometric structure (e.g. tetrakaidecahedron) with scan data of $d_{p}$ and $d_{f}$ to estimate the surface to volume ratio of the foam. This resulted in a number of different models (some are listed by Mahjoob and Vafai [45]). In a recent paper Schmieren and Razani [46] used computed tomography to study a series of aluminum foam samples. They reported a large standard deviation (28\%) of the mean value for $\mathrm{d}_{\mathrm{f}}$, which is due ligament thinning (as the ligaments become longer, they become stretched). Care should thus be taken when determining an 'average' value for $\mathrm{d}_{\mathrm{f}}$ based on data from small samples (optical microscopy). They also showed that 
depending on the relative density of the foam, the actual shape of the ligaments differs, becoming less spherical (up to a triangular shape) as the density decreases. To process the foam images taken by microscopy various types of image processing software and algorithms are used. These filter the grey scale images and define the object perimeter based on a 'cut-off' value. This can introduce significant uncertainty. When comparing their results with data published in literature, Schmieren and Razani [46] found a considerable difference for the specific surface area, up to $40 \%$. Based on a thorough error analysis Schmieren and Razani [46] reported an uncertainty of $18 \%$ on their specific surface area values. A similar technique was used to determine the specific surface area of the foams studied in this research program. Using these measured values for $A_{\text {ext }}$ would result in Nusselt numbers with a large uncertainty which have little value for comparison. Moffat et al. [47] also noted this and proposed to "simply keep the parameters $\left(\mathrm{h}_{\mathrm{ext}}\right.$ and $\left.\mathrm{A}_{\mathrm{ext}}\right)$ as one entity" and this to prevent misinterpretation when comparing data from different sources. Therefore the authors opted to present the heat transfer results in the form of the exterior heat transfer resistance (Eq. (9)) and not as a Nusselt number. In the uncertainty analysis a 5\% uncertainty value was assumed for the thermal conductivity of the aluminum tube and of the epoxy glue. For the pressure drop another complexity arises. As shown by Straatman et al. [32] air flowing parallel to a foam covered surface will penetrate a few $\mathrm{mm}$ into the foam. The depth to which air enters the foam is expected to be a function of the porosity and the foam structure. The aluminum foam used in this research study has a more open structure than the carbon foam used by Straatman et al. [32]. So it is easier for air to enter the foam and pass through it. But as the foam is wrapped around the tube, it is locally compressed near the tube wall, increasing the relative density and making it harder for the air to reach the tube wall. As the impact of the foam height will also be studied, it is difficult to estimate just how much of the exterior surface area is exposed to the air stream for the different scenarios. So based on this, the pressure drop $\Delta \mathrm{p}$ will be reported and not a friction factor.

\section{Results and discussion}

\subsection{Measurement uncertainties}

As stated above, a thorough uncertainty analysis was performed using the procedures found in Moffat [39]. The MTD method, as described by e.g. Shah and Sekulic [1] was used in the uncertainty analysis as using the effectiveness-NTU relationships resulted in unrealistic values. As the correction factor F in the MTD method has to be obtained graphically (value of $0.98-0.99$ ) an uncertainty of 0.05 was assumed on this

value in the calculations. The uncertainty on $\dot{Q}_{m}$ ranged from $1.5 \%$ to $4.3 \%$ (average: $2.6 \%$ ); on $\Delta \mathrm{T}_{\text {air }}$ from $1.7 \%$ to $8.8 \%$ (average: $3.6 \%$ ); on $\Delta \mathrm{T}_{\mathrm{w}}$ from 1.6 to $7.5 \%$ (average: $2.8 \%$ ), on (UA) ${ }^{-1}$ from $5.2 \%$ to $7.5 \%$ (average: $5.8 \%$ ), on $R_{\text {ext }}^{*}$ from $6.7 \%$ to $10.8 \%$ (average $7.6 \%$ ) and on $\Delta \mathrm{p}_{\text {air }}$ from $0.2 \%$ to $5.6 \%$ (average: $1.6 \%)$ 


\subsection{Test set-up benchmark}

As a reference case for the measurements with foam covered tubes, and in order to benchmark the test setup, a series of experiments was done with a single row of plain tubes. The same aluminum tubes as those that were covered with foam were used and they were mounted just as the foam covered tubes with regard to the transversal tube pitch and the water side tube layout (2 pass). The results are presented in Fig. 4. As a comparison the correlation of Gnielinski [48] was used to compute the heat transfer for the single row tube bundle. Although a very large number of correlations have been published with regards to heat transfer and pressure drop in tube bundles, most of these consider very large bundles $(\mathrm{N}>8)$. Almost no correlations consider a single tube row heat exchanger. Wang et al. [49] studied the heat transfer and pressure drop of shallow tube bundles $(\mathrm{N}=1,2,4$ and 6) with plain tubes and compared the results to existing correlations. They found the correlation of Gnielinski [48] resulted in the most accurate prediction of the heat transfer of the bundles, with a mean deviation of $5.3 \%$. As can be seen in Fig. 4A, the agreement between the correlation and the experimental data is quite good for all but $X_{T}^{*}=3.57$, as the various data points and error flags overlap. The experimental data does seem to suggest that the correlation underestimates the impact of the transversal pitch on the heat transfer, as the experimental spread is much larger than that of the correlation. This can be attributed to the correlation being fitted to a dataset of single row heat

exchangers having values of $X_{T}^{*}$ ranging between 1.19 and 2.63 and just one sample with $X_{T}^{*}=3$. For each measured data series, a power relationship (Eq. (10)) was fitted and the corresponding coefficients a and $\mathrm{b}$ are listed in Table 2. These relationships were used further on for comparison between plain and foam covered tubes.

$$
R_{e x t}=a \cdot \operatorname{Re}_{d}^{b}
$$

In Fig. 4B a comparison is shown between the measured pressure drop over the single row of plain tubes and the predicted pressure drop by the correlation of Zukauskas and Ulinskas [50]. This correlation was originally presented in graphical form, listing the Euler number for different configurations combined with a set of power-law fitted curves. Khan et al. [51] digitized the graphical forms and performed a data reduction resulting in a single set of equations to determine the pressure drop of staggered and inline tube bundles. These equations (for an inline bundle with $X_{l}^{*}=X_{t}^{*}$ ) were used to evaluate the pressure drop. As can be seen, and this was also noted by Wang et al. [49], the Zukauskas and Ulinskas [50] correlation underestimates the pressure drop. Wang et al. [49] presented a correction factor, but this factor was found to show very erratic variations in the considered range of $X_{T}^{*}$, so it was not used. The good agreement between the experimental data and the predictions for $X_{T}^{*}=3.57$ (Fig 4B) should be considered coincidental, as the correlation is only valid for $1.25 \leq X_{T}^{*} \leq 3$. No other correlation was found in open 
literature which was applicable to this kind of geometry. Similar as for the $\mathrm{R}_{\mathrm{ext}}$ a curve fit (Eq. (11)) was determined for the pressure drop, the coefficients are listed in Table 2.

$$
\Delta p=c \cdot V_{i n}^{2}-d \cdot V_{i n}
$$

The good agreement between the measured and predicted exterior convective resistance values provides a sufficient benchmark for the test set-up. In addition, a single row heat exchanger with helically finned tubes that was previously studied (Huisseune et al. [52]) was remounted and the heat transfer and pressure drop were measured over a range of air side Reynolds numbers. The results agreed too within the uncertainty of the proposed correlation, further validating the setup. In the remainder of the work the measured exterior convective resistance and pressure drop of the plain tube bundle will be used as a reference value for the foam covered tubes.

\subsection{Convective resistance and pressure drop of the foam covered tubes}

A large number of heat transfer measurements were done on the foam covered tubes. The impact of four parameters was studied: the air inlet velocity $(0.75-7.7 \mathrm{~m} / \mathrm{s})$, the tube spacing (see Eq. (1)), the foam height $(4,6$ or $8 \mathrm{~mm})$ and the foam type (see Table 1 for the properties). The results will be summarized here. To verify the quality of the measurements a heat exchanger that was tested at the start of the measurement campaign was retested at the end of the campaign. The results agreed to within the uncertainty range. Because the batch process used to create the tubes can result in some slight differences between the individual tubes, a test was done to verify the impact of these variations: a tested heat exchanger was dismantled, the individual tubes were permutated in a random order, and then the exchanger was remounted and retested. The results agreed to within the uncertainty range. As stated above the heat transfer results will be represented using the exterior convective resistance $R_{e x t}^{*}$. Only part of the results will be presented, and used to show the trends present within the data. These trends were present within the entire data-set for the different foam types, foam heights or tube spacing.

\subsubsection{Impact of the foam height}

Figure 5A shows $R_{e x t}^{*}$ for foam $1(\varepsilon=0.913)$ for a single tube spacing $\left(X_{T}^{*}=2.38\right)$ set out against the mean inlet velocity $\mathrm{V}_{\text {in }}$. As can be seen, increasing the velocity reduces the exterior convective resistance and this is due to an increase of the convective heat transfer coefficient $h_{\text {ext }}$ (thinner boundary layers, increased turbulence in the foam - better flow mixing). As is expected, increasing the foam height results in a lower value of $R_{\text {ext }}^{*}$, because a higher foam layer results in an increase of $\mathrm{A}_{\text {ext. }}$ The data in Fig. 5A also suggests that the relative gain of adding more surface decreases: the data points for 6 and $8 \mathrm{~mm}$ foam height start to converge at high velocity while the relative surface area increase compared to $4 \mathrm{~mm}$ foam height is 1.55 and 2.2 respectively. To further investigate the gain of increased foam height, the ratio of the 
heat transfer coefficients $h^{\prime}$ is shown in Fig. 5C. These values are determined from the ratio of $R_{\text {ext }}^{*}$ and the surface area ratio (Eq. (12)). If local compression phenomena are ignored, the specific surface area of the foam is constant and thus the surface ratio becomes equal to the ratio of the foam height.

$$
h^{\prime}=\frac{h_{H=H_{1}}}{h_{H=H_{2}}}=\frac{R_{e x t, H=H_{2}}^{*}}{R_{e x t, H=H_{1}}^{*}} \cdot \frac{A_{H=H_{1}}}{A_{H=H_{2}}}
$$

If the flow would penetrate the foam in a uniform way, the values for $h^{\prime}$ would be 1 . Instead, the data in Fig. 5C clearly show (much) lower values which decrease as the foam height increases. This shows that the flow only penetrates the foam to a certain depth, as had been previously found for carbon foams on a flat surface by Straatman et al. [32]. So even though the values of $R_{e x t}^{*}$ decrease with increasing foam height, the foam itself is used less effectively. There are also significant differences between the different foams, as shown in Fig. 5C. Increasing the foam height also results in a very significant increase in the pressure drop, as shown in Fig. 5B. If one assumes the air flow penetrates the foam for a fixed distance (independent of the height) than increasing the foam height exposes the air to more surface area (and thus reduces $R_{\text {ext }}^{*}$ ), while at the same time the flow experiences more friction due to the increased surface area as well as a strong contraction effect between the foam covered tubes. This effect is most pronounced for the smallest tube spacing $\left(X_{T}^{*}=2.38\right.$, Fig. 5B). The foam covered tubes with $8 \mathrm{~mm}$ foam height almost made contact at this spacing ( $0.6 \mathrm{~mm}$ of free space), which explains the very high pressure drop. These findings are similar to those of Jamin and Mohamad [33] who found that for a tube covered with a sleeve of carbon foam increasing the sleeve diameter resulted in only a small increase of the Nusselt number, but a very sharp rise of the pressure drop (note the logarithmic scale in Fig. 5B). These results indicate a need for more research, specifically towards smaller sleeve diameters: 1-3 mm. This data could be valuable to determine the actual penetration depth and provide a more solid basis to determine the merit of foam covered tubes.

To determine the performance of the foamed tube heat exchanger, a 'performance evaluation criterion' or PEC will be used. A large number of different criteria exist, e.g. the surface and volume goodness as defined by Kays and London [35]. A detailed summary is provided by Cowell [53]. Considering the uncertainty on the specific surface of the foam (as discussed above) and the availability of both heat transfer and pressure drop data for the reference surface (plain tube, see Table. 2) it was selected to compare the performance based on the reference surface: Eq. (13). Using the definition of the Colburn jfactor and friction factor, the PEC can be written as a function of the exterior convective resistance, the pressure drop and the surface geometry, resulting in Eq. (14). The only unknown is the minimal free flow area $A_{c}$ for the foam covered tubes. As was shown above, the flow does penetrate the foam but only to a certain depth. So assuming that $\mathrm{A}_{\mathrm{c}}=\mathrm{A}_{\mathrm{c}, \text { ref }}$ or that $\mathrm{A}_{\mathrm{c}}$ can be determined by considering the foam as a blunt 
object is both incorrect. By examining the dataset it was estimated that the air penetrated between 3 and 5 $\mathrm{mm}$ into the foam, so the average value of $4 \mathrm{~mm}$ was used as a penetration depth to determine $\mathrm{A}_{\mathrm{c}}$.

$$
\begin{gathered}
P E C=\frac{j}{j_{r e f}} \cdot \frac{f_{r e f}}{f} \\
P E C=\frac{R_{\text {ext }, \text { ref }}}{R_{\text {ext }}^{*}} \cdot \frac{\Delta p_{\text {ref }}}{\Delta p} \cdot\left(\frac{A_{c, r e f}}{A_{c}}\right)^{2}
\end{gathered}
$$

Figure 5D presents the value of the PEC for 2 different tube spacings with varying foam height $(\varepsilon=0.913)$. As can be seen, increasing the foam height for the largest tube spacing has only a small effect, as for $\mathrm{H}_{\text {foam }}$ $=8 \mathrm{~mm}$ a reduction of the PEC can be seen. This indicates that the relative gain in heat transfer of adding more surface area is no longer outweighed by the added pressure drop. For $\mathrm{H}_{\text {foam }}=8 \mathrm{~mm}$ the performance is even worse than that of the plain tube bundle. This is due to the bonding resistance which substantially reduces the heat transfer rate, as shown further on. At the smallest tube spacing the effects are much more pronounced. As can be seen, increasing the foam height results in a sharp drop of the PEC due to the strong rise in pressure drop, which is consistent with earlier findings. It should be stressed that this PEC is just one of many ways to consider the 'benefit' of using foam covered tubes. Depending on the actual application the PEC could have an entirely different form, incorporating e.g. manufacturing costs, volume, weight...

\subsubsection{Impact of the tube spacing}

Reducing the tube spacing for a fixed foam height results in a larger contraction of the free flow area. This increases the air velocity in between the tubes, which will result in higher convective heat transfer coefficients, and thus reduce the $R_{\text {ext }}^{*}$ values. At the same time this results in a large increase of the pressure drop. This can be seen in Fig. $6\left(\mathrm{H}_{\text {foam }}=4 \mathrm{~mm}, \varepsilon=0.913\right)$. The smallest tube pitch results in the highest values of the PEC, while the intermediate pitches (as can be seen in Fig. 5D: $X_{T}^{*}=3.06$ and 2.68) result in quite similar values. This was the case for all foam types with a foam height of $4 \mathrm{~mm}$. This suggests that the added pressure drop of spacing the tubes closer together is outweighed by the reduction in heat transfer resistance. Figures 5D and 7C also shows that the PEC values increase up to a given velocity range and then stabilize. This suggests the foams need a certain air velocity to perform well. Depending on the configuration this velocity ranges between 4 and $6 \mathrm{~m} / \mathrm{s}$. Similar to Straatman et al. [32] it was found that at low Reynolds numbers the heat transfer enhancement (ratio of the Nusselt numbers) is higher than at high Reynolds numbers, but the pressure drop increase at low Reynolds numbers outweighs the benefit.

\subsubsection{Impact of the foam type}

Four different types of foam were used. The geometric parameters can be found in Table 1. Figure 7 shows the values of $R_{e x t}^{*}, \Delta \mathrm{p}$ and the PEC for the different foam types $\left(\mathrm{H}_{\mathrm{foam}}=4 \mathrm{~mm}, X_{T}^{*}=2.38\right)$. As can be seen there is quite some difference between the various foams. Foam 1 results in the highest PEC values 
and this due to having the lowest $R_{\text {ext }}^{*}$ combined with a moderate pressure drop. Foam 2 on the other hand has the highest pressure drop and $R_{\text {ext }}^{*}$ values, resulting in the lowest PEC values. Foam 4 has the second best performance. Comparing the geometric data of the various foams shows that foam 1 and 4 both have a high specific surface area and 20 ppi. It is remarkable that foam 1 has the lowest porosity of all foams, and has the best performance. Foams 2 and 4 have a similar porosity but the performance is quite different. Foams 2 and 3 have similar values for the specific surface area and pore diameter, but quite different strut diameters, which results in a higher PEC value for foam 3. This shows that only porosity is not a good parameter to relate the thermo-hydraulic behaviour too, the pore and strut diameter should be used. The results indicate that foams with small pores and struts will result in a better performance.

\subsubsection{Impact of the bonding resistance}

Recalling Eq. (9) it is possible to estimate the impact of the bonding resistance on the measured results by modeling the layer of epoxy as a cylinder surrounding the tube: Eq. (15). Based on destructive testing of a number of tubes after they were dismantled, it was found that the average thickness of the epoxy glue used to connect the foam to the tube was between $0.3 \mathrm{~mm}$ and $0.6 \mathrm{~mm}$. So as a conservative estimate a value of $0.3 \mathrm{~mm}$ was used in further analysis. It was found that the contribution of $\mathrm{R}_{\text {bond }}$ to the overall heat transfer resistance $\mathrm{R}_{\mathrm{ov}}$ varied between $6 \%$ and 55\%, indicating a really significant impact of the bonding method. The impact increased as the air velocity and foam height became higher and the tube spacing became smaller, due to the increased convective heat transfer coefficient. This is shown in Fig. 8. These trends make sense, as the bonding resistance is a fixed contribution (depending only on the geometry and the thermal conductivity of the epoxy) to the total resistance, and these factors help in reducing the value of $\mathrm{R}_{\mathrm{ov}}$. These findings are in agreement with the work of Batawros et al. [27] and Sekulic et al. [54]. The latter compared brazed and unbrazed metal foam heat exchangers and showed that by brazing the foam to the contact surface a much greater heat transfer enhancement can be achieved. More research is needed in this field to develop efficient and cost-effective brazing methods for metal foams to tubes to provide solid metallic bonds.

$$
R_{\text {bond }}=\frac{\ln \left(\frac{d_{\text {ext }}+2 \cdot H_{\text {exp oxy }}}{d_{\text {ext }}}\right)}{2 \cdot \pi \cdot k_{\text {epoxy }} \cdot L_{T}}
$$

\subsubsection{Comparison to helically finned tubes}

In this final section a brief comparison will be shown between the performance of the foam covered tubes and helically monofinned tubes, as studied by Huisseune et al. [52]. The geometric parameters of these tubes are: $\mathrm{d}_{\text {int }}=0.010 \mathrm{~m}, \mathrm{~d}_{\mathrm{ext}}=0.013 \mathrm{~m}, \mathrm{~d}_{\text {fin }}=0.0248 \mathrm{~m}, \mathrm{t}_{\text {fin }}=0.0008 \mathrm{~m}$ and $\mathrm{F}_{\mathrm{p}}=0.0024 \mathrm{~m}$. Figure $9 \mathrm{~A}$ and $\mathrm{B}$ contains the values of $R_{e x t}$ and $\Delta \mathrm{p}$ respectively for foam covered tubes with varying foam height ( $X_{T}^{*}=$ 
$2.38, \varepsilon=0.913$ ) and the corresponding values for plain tubes and helically finned tubes. Figure $9 \mathrm{C}$ reports the accompanying PEC values. As can be seen in Fig. 9 A, the helically finned tubes result in low $\mathrm{R}_{\mathrm{ext}}$ values with a pressure drop equal to that of the foam covered tube with $4 \mathrm{~mm}$ foam height. As the foam height increases the $\mathrm{R}_{\mathrm{ext}}$ values for the foam covered tubes decrease but the pressure drop increases. As a result the PEC values for the helically finned tubes are always higher than that of foam covered tubes (full symbols Fig. 9 C), despite the foam covered tubes with $8 \mathrm{~mm}$ foam having $\mathrm{R}_{\mathrm{ext}}$ values comparable to those of the helically finned tubes. But if one considers the strong impact of the bonding resistance and the bonding resistance is reduced ( $\sim$ using Al-Si brazing to connect the foam to the tubes: $\mathrm{k}_{\text {brazing }}=150 \mathrm{~W} / \mathrm{mK}$ ) the results are quite different. As can be seen in Fig. 9 A, the $R_{\text {ext }}$ values drop considerably for the foam covered tubes, particularly at high air velocities. This results in a strong increase of the PEC, making the foam covered tubes perform as good as the helically finned tubes at low inlet velocities and much better at higher velocities, as shown in Fig. $9 \mathrm{C}\left(X_{T}^{*}=2.38\right)$. This once again stresses the need for a good metallic bonding of the foam to the substrate. Remarkable is that the foam covered tubes with $4 \mathrm{~mm}$ high foam results in the highest PEC values. Figure $9 \mathrm{C}$ also shows the impact of the tube spacing on the PEC values of helically finned tubes and foam covered tubes $\left(\varepsilon=0.913, \mathrm{H}_{\text {foam }}=4 \mathrm{~mm}\right.$, without bonding resistance). As can be seen reducing the tube spacing results in lower PEC values for both tube types. The drop off for the foam covered tubes is stronger than for the helically finned tubes, as the foam covered tubes with $X_{T}^{*}$ values 2.68 and 3.06 only just outperform the helically finned counterparts.

\section{Conclusions}

This work reports on the results of a thermo-hydraulic study of single row heat exchangers consisting of aluminum tubes covered with metal foam. The impact of various parameters was considered: the Reynolds number, the tube spacing, the foam height and the type of foam. A comparison of the performance of foam covered tubes with different foam height clearly showed that increasing the foam height reduces the exterior convective resistance, while at the same time increasing the pressure drop. It was also found that the air only penetrates the foam to a certain extent, which results in a decreasing performance as the foam height increases. Comparing the performance of heat exchangers with a different tube layout showed that although the smallest tube spacing resulted in the highest pressure drop, it also provided the largest heat transfer benefit, and thus has the best performance. A comparison of the data for different foams indicated that porosity on its own is not a good parameter to quantify foam data with; rather the pore diameter and strut diameter and the related specific surface area should be used. An investigation into the impact of the bonding resistance showed that using epoxy glue can have devastating effects on the heat exchanger performance. More research is required into securing a cost-effective and efficient brazing process to connect metal foams to the tube surfaces. If this bonding can be achieved, metal foam covered tubes with a 
small tube spacing, small foam heights and made of foam with a high specific surface area and thin struts potentially offer strong benefits at higher air velocities $(>4 \mathrm{~m} / \mathrm{s})$ compared to helically finned tubes.

\section{Acknowledgments}

The authors would like to express gratitude to Bekaert for the close cooperation. The Flemish Research Foundation (FWO Vlaanderen) and the Institute for the Promotion of Innovation by Science and Technology (IWT Vlaanderen) are greatly acknowledged for their financial support.

\section{References}

[1] R.K. Shah, D.P. Sekulic, Fundamentals of Heat Exchanger Design, John Wiley \& Sons, Inc., Hoboken, New Jersey, 2003.

[2] A.M. Jacobi, R.K. Shah, Air side flow and heat transfer in compact heat exchangers: a discussion of enhancement mechanisms, Heat Transfer Engineering 19 (1998) 29-41.

[3] A.M. Jacobi, R.K., Shah, R.K., Heat Transfer Surface Enhancement through the Use of Longitudinal Vortices - a review of recent progress, Experimental Thermal and Fluid Science 11 (1995) 295-309.

[4] H.N.G. Wadley, Multifunctional periodic cellular metals, Philosophical Transactions of the Royal Society A 364 (2006) 31-68.

[5] L. Tuchinskiy, Novel fabrication technology for metal foam, Journal of Advanced Materials 37 (2005) 60-65.

[6] P.S. Liu, K.M. Liang, Functional materials of porous metals made by P/M, electroplating and some other techniques, Journal of Materials Science 36 (2001) 5059-5072.

[7] T.J. Lu, L. Valdevit, A.G., Evans, Active cooling by metallic sandwich structures with periodic cores, Progress in Materials Science 50 (2005) 789-815.

[8] M. Kaviany, Principles of Heat Transfer in Porous Media, Springer, New York, 1995.

[9] B. Alazmi, K. Vafai, Analysis of variants within the porous media transport models, Transactions of the ASME: Journal of Heat transfer 122 (2000) 303-326.

[10] V.V. Calmidi, R.L. Mahajan, Forced convection in high porosity metal foams, Transactions of the ASME - Journal of Heat Transfer 122 (2000) 557-565.

[11] K. Boomsma, D. Poulikakos, On the effective thermal conductivity of a three dimensionally structured fluid saturated metal foam, International Journal of Heat and Mass Transfer 44 (2001) 827-836

[12] R. Singh, H.S. Kasana, Computational aspects of effective thermal conductivity of highly porous metal foams, Applied Thermal Engineering 24 (2004) 1841-1849

[13] D. Angirasa, Forced convective heat transfer in metallic fibrous materials, Transactions of the ASME Journal of Heat Transfer 124 (2002) 739-745.

[14] J. Banhart, Manufacture, characterization and application of cellular metals and metal foams, Progress in Material Science 46 (2001) 559-632. 
[15] S. Mahjoob, K. Vafai, A synthesis of fluid and thermal transport models for metal foam heat exchangers, International Journal of Heat and Mass Transfer 51 (2008) 3701-3711

[16] V. Cnudde, B. Masschaele, M. Dierick J. Vlassenbroeck, L. Van Hoorebeke, P. Jacobs, Recent progress in X-ray CT as a geosciences tool, Applied Geochemistry 21 (2006) 826-832

[17] B.C. Masschaele, V. Cnudde, M. Dierick, P. Jacobs, L. Van Hoorebeke, J. Vlassenbroeck,, UGCT:

New X-ray radiography and tomography facility, Nuclear Instruments \& Methods in Physics Research 580 (2007) 266-269

[18] J. Vlassenbroeck, M. Dierick, B. Masschaele, V. Cnudde, L. Van Hoorebeke, P. Jacobs, Software tools for quantification of X-ray microtomography at the UGCT, Nuclear Instruments \& Methods in Physics Research 580 (2007) 442-445

[19] K. Boomsma, D. Poulikakos, F., Zwick, Metal foams as compact high performance heat exchangers, Mechanics of Materials 35 (2003) 1161-1176.

[20] L. Tadrist, M. Miscevic, O. Rahli, F. Topin, About the use of fibrous materials in compact heat exchangers, Experimental Thermal and Fluid Science 28 (2004) 193-199.

[21] S.Y. Kim, J.W., Paek, B.H., Kang, Flow and heat transfer correlations for porous fin in a plate-fin heat exchanger, Transactions of the ASME: Journal of Heat transfer 122 (2000) 573-578.

[22] W.H. Hsieh, J.Y. Wu, W.H. Shih, W.C. Chiu, Experimental investigation of heat-transfer characteristics of aluminum foam heat sinks, International Journal of Heat and Mass Transfer 47 (2004) 5149-5157.

[23] W.H. Shih, W.C. Chiu, W.H. Hsieh, Height effect on heat transfer characteristics of aluminum foam heat sinks, Transactions of the ASME: Journal of Heat transfer 128 (2006) 530-537.

[24] Y. Kim, J.W. Paek, B.H. Kang, B.H., Thermal performance of aluminum-foam heat sinks by forced air cooling, IEEE Transactions on Components and Packaging Technologies 26 (2003) 262-267.

[25] A. Bhattacharya, R.L. Mahajan, Finned metal foam heat sinks for electronics cooling in forced convection, Transactions of the ASME: Journal of Electronics Packaging 124 (2002) 155-163

[26] A. Bhattacharya, R.L. Mahajan, Metal foam and finned metal foam heat sinks for electronics cooling in buoyancy-induced convection, Transactions of the ASME: Journal of Electronics Packaging 128 (2006) 259-266

[27] A.F. Bastawros, A.G. Evans, A.G., Characterization of open cell aluminum alloy foams as heat Sinks for high power electronic devices, Proceedings of the ASME Conference on CAE/CAD and Thermal Management Issues in Electronic Systems, EEP-23/HTD-356, Dallas, 1997.

[28] J.W. Klett, R. Ott, A. McMillan, Heat exchangers for heavy vehicles utilizing high thermal conductivity graphite foam, SAE2000-01-2207, Proceedings of the 2000 SAE World Conference, Chicago, 2000.

[29] N.C. Gallego, J.W. Klett, Carbon foams for thermal management, Carbon 41 (2003) 1461-1466. 
[30] K.C. Leong, H.Y. Li, L.W. Jin, J.C. Chai, Convective heat transfer and fluid flow characteristics of graphite foam heat sinks with complex structures, Proceedings of the $7^{\text {th }}$ World Conference on experimental heat transfer, fluid mechanics and thermodynamics, Krakow, Poland, 2009.

[31] K. Sumithra Raju, A. Narasimhan, A., Porous medium interconnector effects on the thermohydraulics of near-compact heat exchangers treated as porous media, Transactions of the ASME: Journal of Heat transfer 129 (2007) 273-281.

[32] A.G. Straatman, N.C. Gallego, B.E. Thompson, H. Hangan, Thermal characterization of porous carbon foam - convection in parallel flow, International Journal of Heat and Mass Transfer 49 (2006) 1991-1998

[33] Y.L. Jamin, A.A. Mohamad, Enhanced heat transfer using porous carbon foam in cross flow - part 1: forced convection, Transactions of the ASME: Journal of Heat transfer 129 (2007) 735-742.

[34] I. Ghosh, How good is open-cell metal foam as heat transfer surface, Transactions of the ASME: Journal of Heat transfer 131 (2009) 101004-1 - 101004-8.

[35] W.M. Kays, A.L. London, Compact Heat Exchangers, 3d ed., McGraw-Hill, New York, 1984.

[36] C. T'Joen, H.J. Steeman, A. Willockx, M. De Paepe, Determination of Heat Transfer and Friction Characteristics of an Adapted Inclined Louvered Fin, Experimental Thermal and Fluid Science 30 (2006) 319-327.

[37] C. T'Joen, A. Willockx, H.J. Steeman, M. De Paepe, Performance Prediction of Compact Fin-andTube Heat Exchangers in Maldistributed Airflow, Heat Transfer Engineering 28 (2007) 986-996.

[38] J.W. Rose, Heat transfer coefficients, Wilson plots and accuracy of thermal measurements, Experimental Thermal and Fluid Science 28 (2004) 77-86

[39] R.J. Moffat, Describing the uncertainties in experimental results, Experimental Thermal and Fluid Science 1 (1988) 3-17.

[40] K. Kadoya, N. Matsunaga, A. Nagashima, Viscosity and Thermal- Conductivity of Dry Air in the Gaseous-Phase,” Journal of Physical and Chemical Reference Data 14(4) (1985) 947-970.

[41] IAPWS Release on the IAPWS Formulation 1995 for the Thermodynamic Properties of Ordinary Water Substance for General and Scientific Use (IAPWS-95), 1996. Available at http://www.iapws.org. [42] Revised release on the IAPWS industrial formulation 1997 for the thermodynamic properties of water and steam (IAPWS-IF97), 2007. Available at http://www.iapws.org.

[43] V. Gnielinski, New Equations for Heat and Mass Transfer in Turbulent Tube and Channel Flow, International Chemical Engineering 29 (1976) 359-368.

[44] J.P. Abraham, E.M. Sparrow, J.C.K. Tong, Heat transfer in all pipe flow regimes: laminar, transitional/intermittent, and turbulent, International Journal of Heat and Mass Transfer 52 (2009) 557-563.

[45] S. Mahjoob, K. Vafai, A synthesis of fluid and thermal transport models for metal foam heat exchangers, International Journal of Heat and Mass Transfer 51 (2008) 3701-3711

[46] E.N. Schmieren, A. Razani, Self-consistent open-celled metal foam for thermal applications, Transactions of the ASME: Journal of Heat transfer 128 (2006) 1194-1203. 
[47] R.J. Moffat, J.K. Eaton, A. Onstad, A method for determining the heat transfer properties of foam-fins, Transactions of the ASME: Journal of Heat transfer 131 (2009) 011603-1 - 011603-7.

[48] V. Gnielinski, Gleichungen zur Berechnung des Wärmeübergangs in querdurchströmten einzelnen Rohrreihen und Rohrbündeln, Forschung im Ingenieurwesen 44 (1978) 15-25

[49] C.C. Wang, W.S. Lee, W.J. Sheu, Airside performance of staggered tube bundle having shallow tube rows, Chemical Engineering Communications 187 (2001) 129-147.

[50] A. Zukauskas, R. Ulinskas, Single phase fluid flow: banks of plain and finned tubes, HEDH - Heat Exchanger Design Handbook, Washington Hemisphere publishing, New York, 1983.

[51] W.A. Khan, J.R. Culham, M.M. Yovanovich, Optimal design of tube banks in crossflow using entropy generation minimization method, Journal of Thermophysics and Heat Transfer 21 (2007) 372-378.

[52] H. Huisseune, C. T'Joen, P. Brodeoux, S. Debaets, M. De Paepe, Thermal hydraulic study of a single row heat exchanger with helically finned tubes, Transactions of the ASME: Journal of Heat transfer (under review)

[53] T.A. Cowell, A general method for the comparison of compact heat transfer surfaces, Transactions of the ASME: Journal of Heat transfer 112 (1990) 288-294.

[54] D.P. Sekulic, Y.M. Dakhoul, H. Zhao, W. Liu, Aluminum foam compact heat exchangers: brazing technology development vs. thermal performance, Proceedings of the Cellmet 2008 Conference, Dresden, , 2008. 


\section{Figure captions}

Fig. 1. Comparison of various cooling methods for a channel: (a) friction factor as a function of the Reynolds number and (b) the Nusselt number as a function of the Reynolds number (Lu et al. [7]).

Fig. 2. Experimental setup: open air wind tunnel and a closed water cycle ( $\rightarrow$ : air flow; $\rightarrow$ : water flow) Fig. 3. A helically finned (top) as studied by Huisseune et al. [52] and metal foam covered tube (bottom).

Fig. 4. Experimentally determined $R_{e x t}^{*}$ (a) and $\Delta \mathrm{p}$ (b) of single row plain tube heat exchangers with varying tube spacing, compared to the predicted values of the Gnielinski [48] the Zukauskas [50] correlation respectively.

Fig. 5. $R_{e x t}^{*}$ (A) and $\Delta$ p (B) for 3 different foam heights set out against the mean inlet velocity, $X_{T}^{*}=2.38$, $\varepsilon=0.913$. Plain tube bundle data shown as reference; $C: h^{\prime}$ for 2 different foam types (relative to $\mathrm{H}_{\text {foam }}=4$ $\mathrm{mm}$ ) set out against the mean inlet velocity, $X_{T}^{*}=2.38$; D: PEC for 3 different foam heights and various tube spacings set out against the mean inlet velocity, $\varepsilon=0.913$.

Fig. 6. $R_{\text {ext }}^{*}$ (A) and $\Delta \mathrm{p}(\mathrm{B})$ for 4 different tube spacings set out against the mean inlet velocity, $\mathrm{H}_{\text {foam }}=4$ $\mathrm{mm}, \varepsilon=0.913$.

Fig. 7. $R_{\text {ext }}^{*}$ (A), $\Delta \mathrm{p}(\mathrm{B})$ and PEC (C) for 4 different foam types set out against the mean inlet velocity, $\mathrm{H}_{\text {foam }}=4 \mathrm{~mm}, X_{T}^{*}=2.38$.

Fig. 8. Relative contribution of the bonding resistance to the overall heat transfer resistance for various configurations, $\varepsilon=0.913$.

Fig. 9. $R_{\text {ext }}$ values (A), $\Delta$ p (B) for foam covered tubes (3 different foam heights), for helically finned tubes and for plain tubes set out against the mean inlet velocity, $X_{T}^{*}=2.38$; (C) corresponding PEC values for various tube spacings, $\varepsilon=0.913$. The open symbols represent theoretical cases where $\mathrm{R}_{\mathrm{bond}}$ was reduced by using Al-Si brazing. 


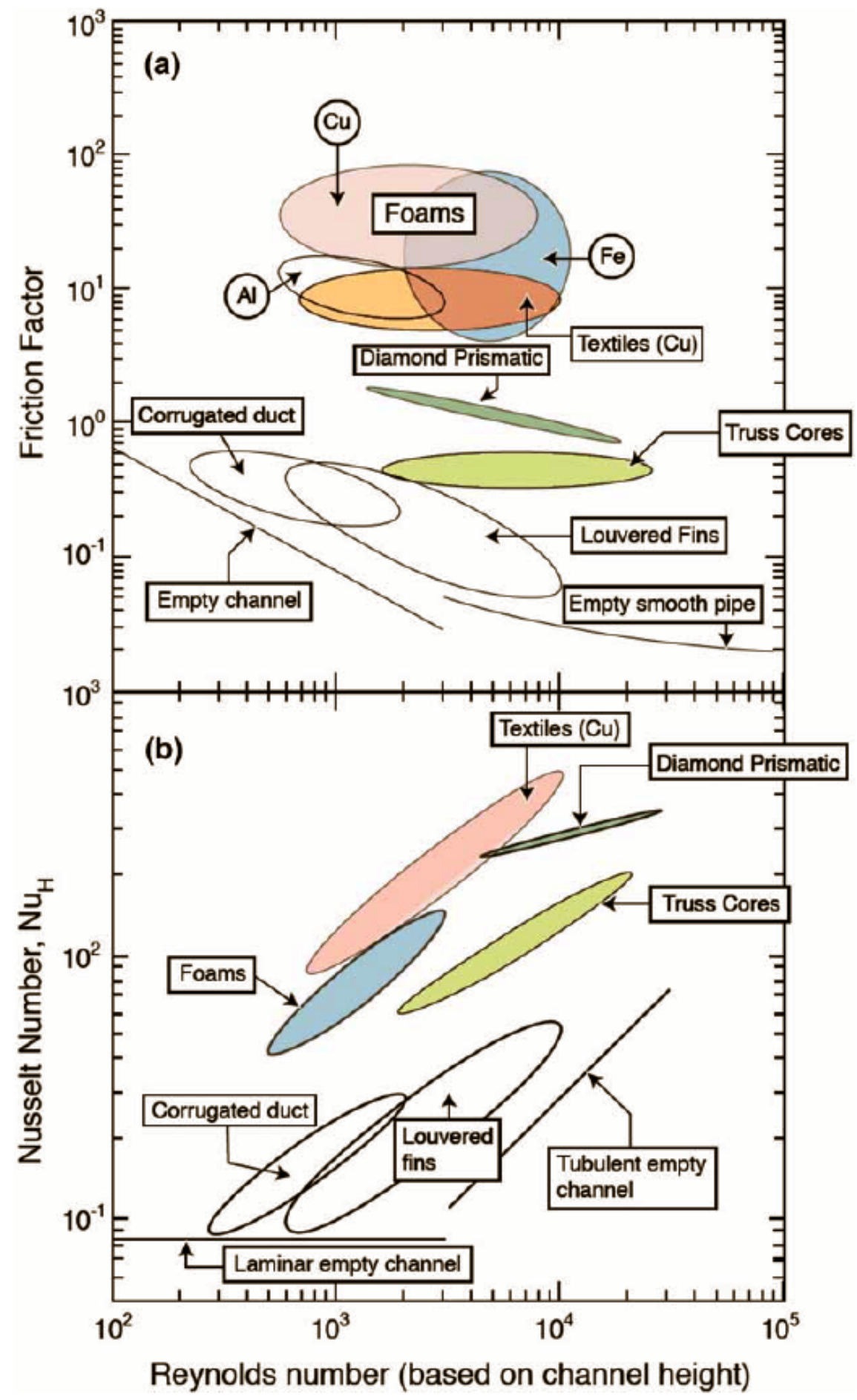

Fig. 1. Comparison of various cooling methods for a channel: (a) friction factor as a function of the Reynolds number and (b) the Nusselt number as a function of the Reynolds number ( $\mathrm{Lu}$ et al. [7]). 


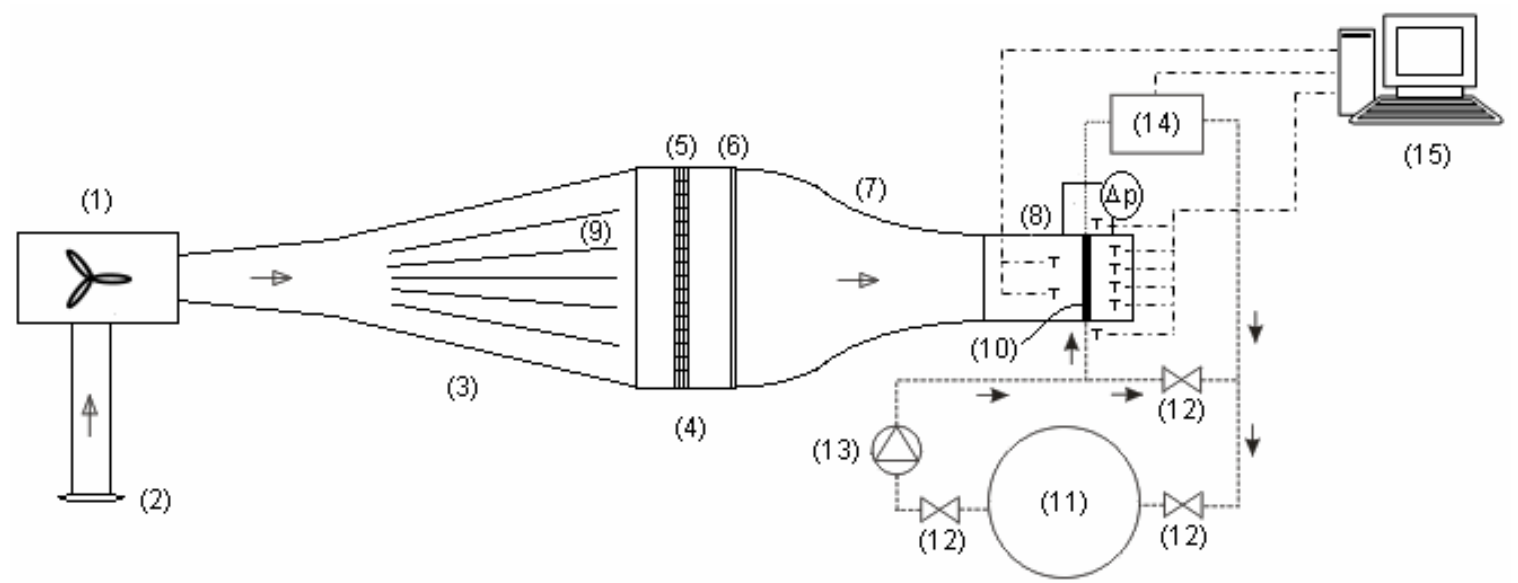

Fig. 2. Experimental setup: open air wind tunnel and a closed water cycle ( $\rightarrow$ : air flow; $\rightarrow$ : water flow) 


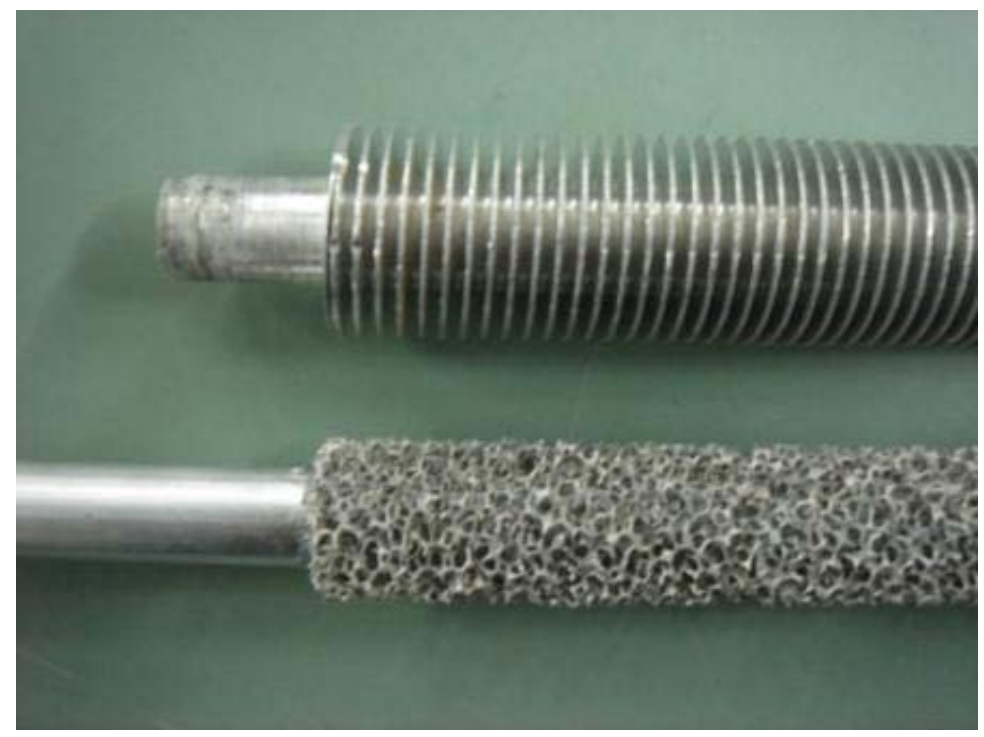

Fig. 3. A helically finned (top) as studied by Huisseune et al. [52] and metal foam covered tube (bottom). 

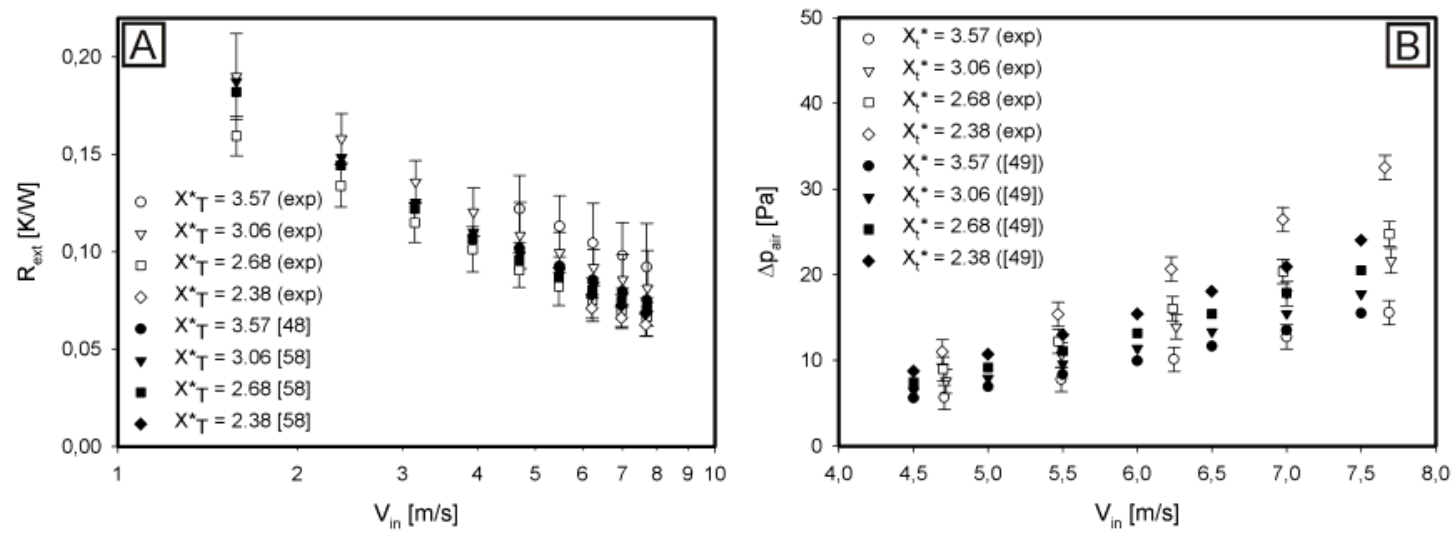

Fig. 4. Experimentally determined $R_{e x t}^{*}$ (A) and $\Delta \mathrm{p}$ (B) of single row plain tube heat exchangers with varying tube spacing, compared to the predicted values of the Gnielinski [48] the Zukauskas [50] correlation respectively. 

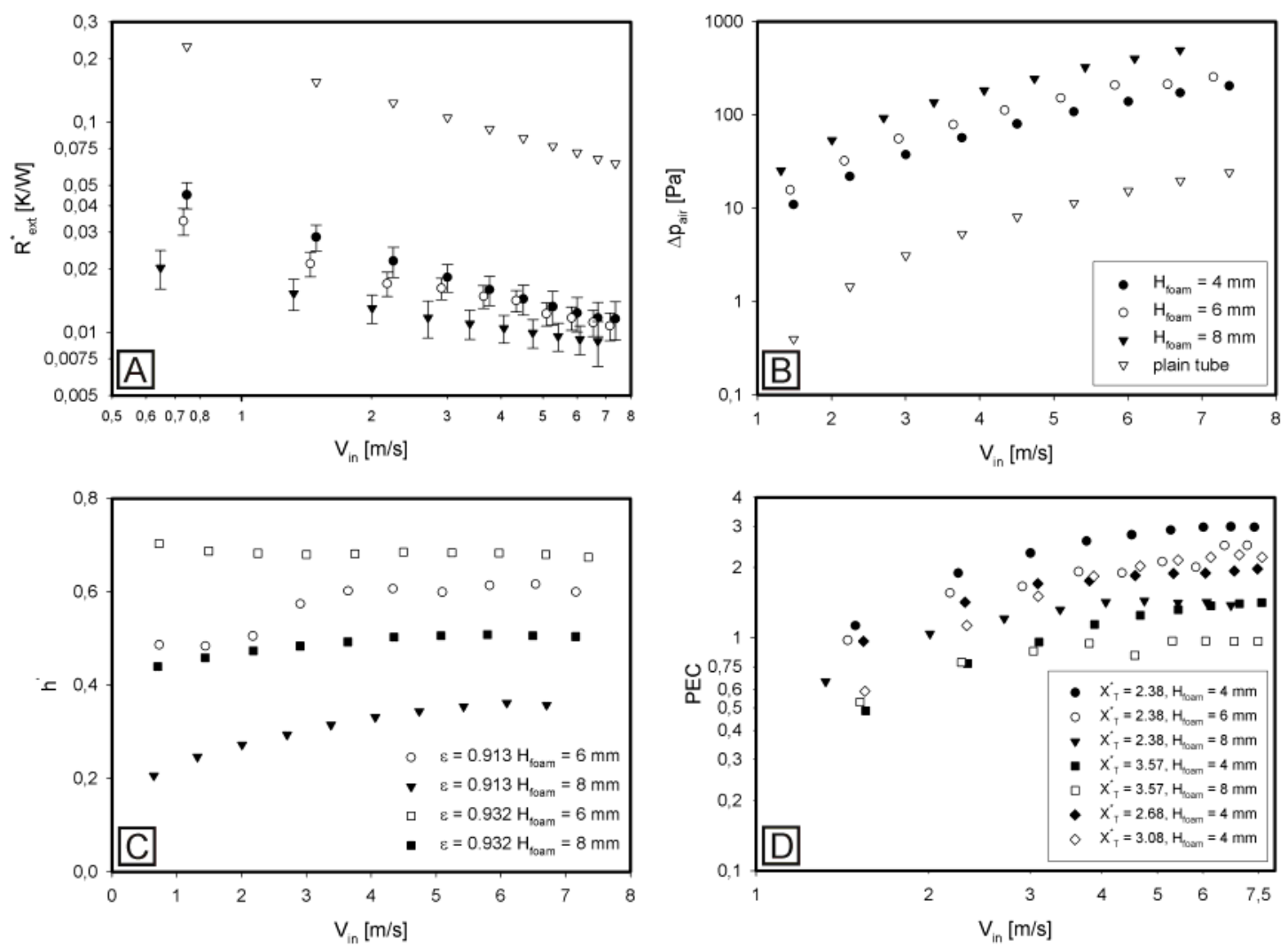

Fig. 5. $R_{\text {ext }}^{*}$ (A) and $\Delta$ p (B) for 3 different foam heights set out against the mean inlet velocity, $X_{T}^{*}=2.38$, $\varepsilon=0.913$. Plain tube bundle data shown as reference; $\mathrm{C}: h^{\prime}$ for 2 different foam types (relative to $\mathrm{H}_{\text {foam }}=4$ $\mathrm{mm}$ ) set out against the mean inlet velocity, $X_{T}^{*}=2.38$; D: PEC for 3 different foam heights and various tube spacings set out against the mean inlet velocity, $\varepsilon=0.913$. 

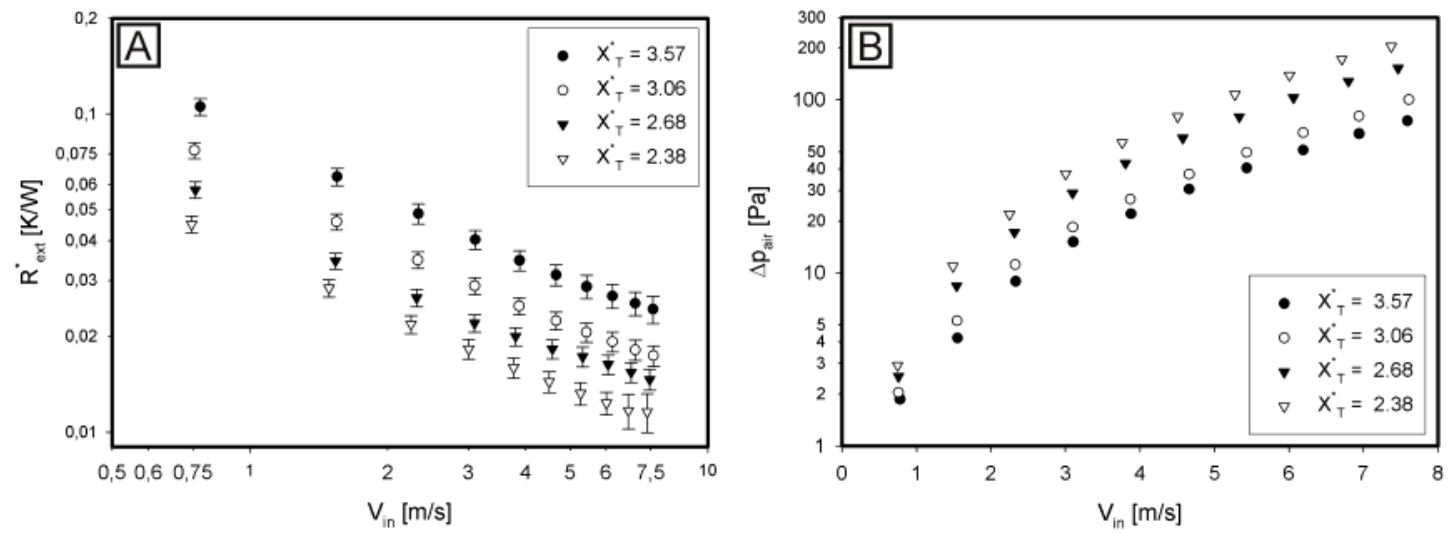

Fig. 6. $R_{\text {ext }}^{*}$ (A) and $\Delta \mathrm{p}(\mathrm{B})$ for 4 different tube spacings set out against the mean inlet velocity, $\mathrm{H}_{\text {foam }}=4$ $\mathrm{mm}, \varepsilon=0.913$. 

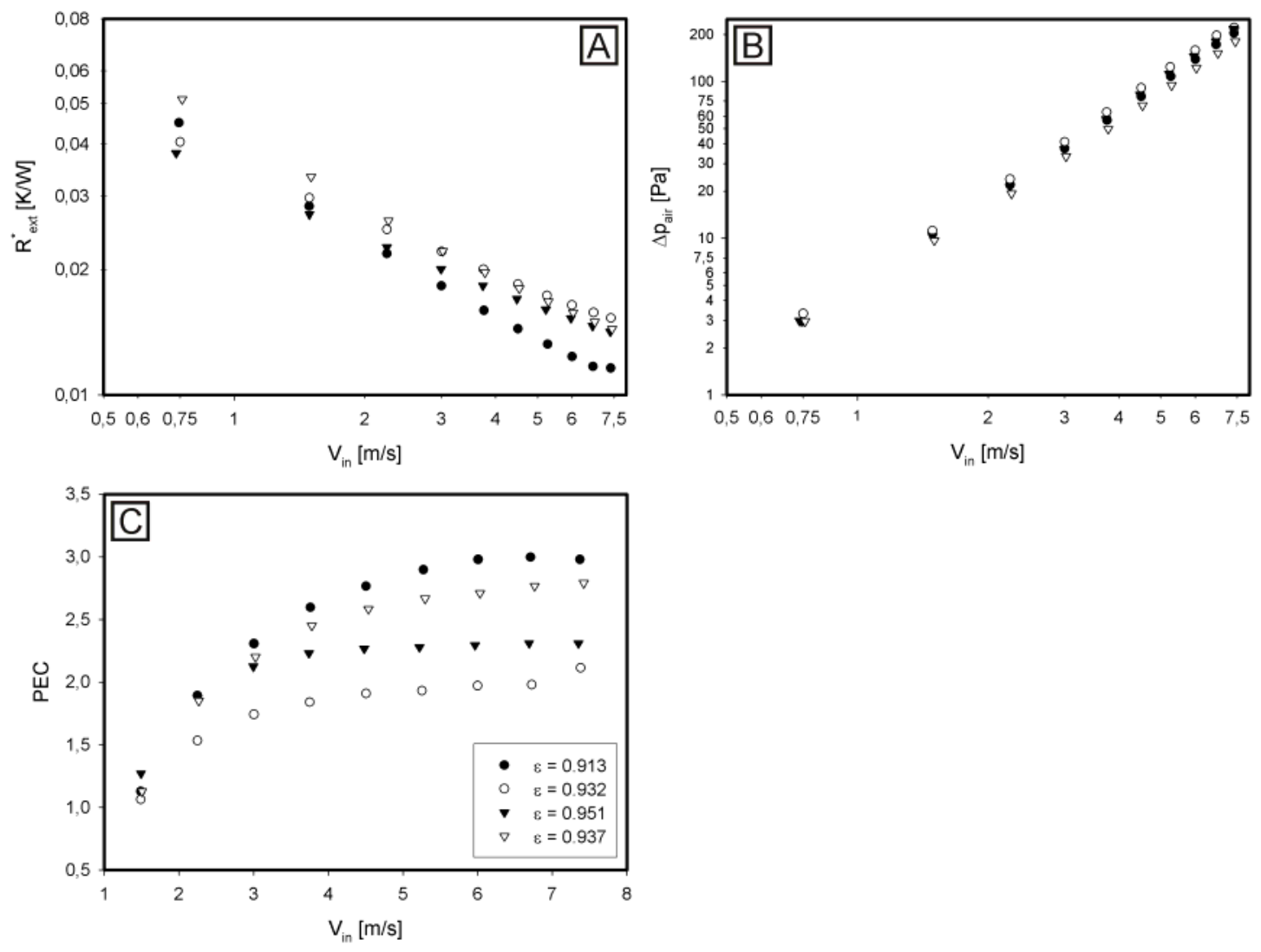

Fig. 7. $R_{e x t}^{*}(\mathrm{~A}), \Delta \mathrm{p}(\mathrm{B})$ and PEC (C) for 4 different foam types set out against the mean inlet velocity, $\mathrm{H}_{\text {foam }}=4 \mathrm{~mm}, X_{T}^{*}=2.38$. 


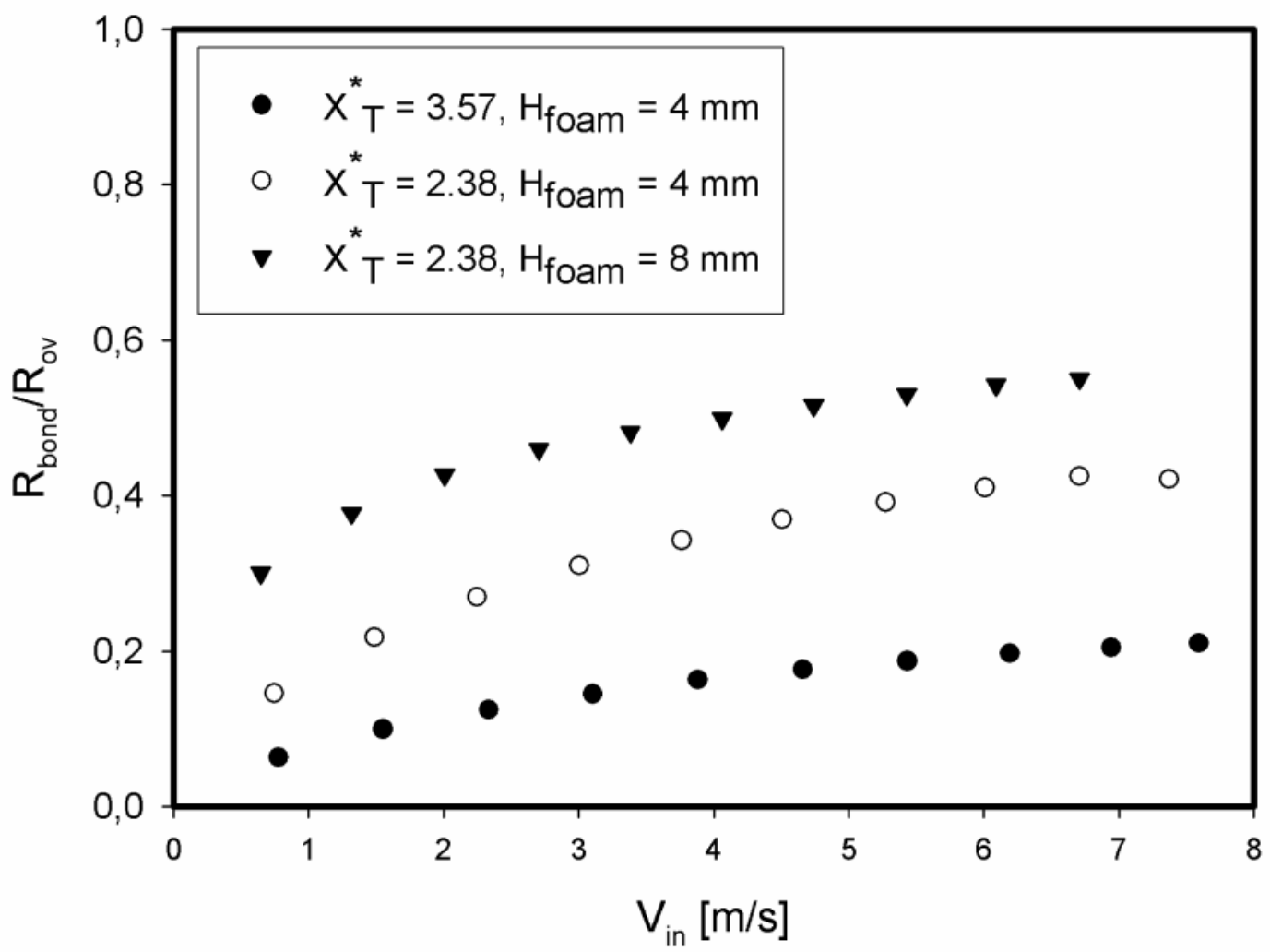

Fig. 8. Relative contribution of the bonding resistance to the overall heat transfer resistance for various configurations, $\varepsilon=0.913$. 

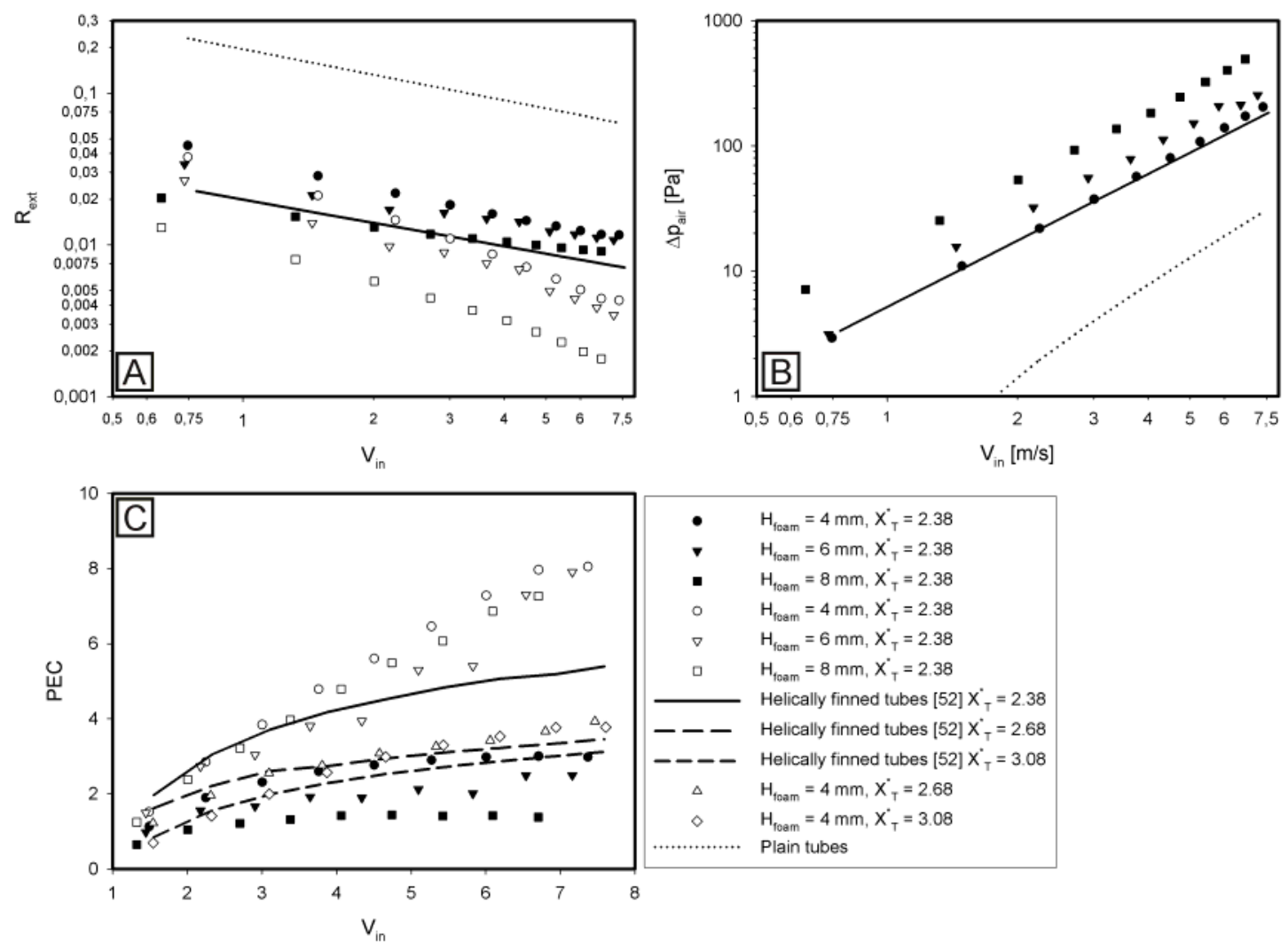

Fig. 9. $R_{\text {ext }}$ values (A), $\Delta \mathrm{p}$ (B) for foam covered tubes (3 different foam heights), for helically finned tubes and for plain tubes set out against the mean inlet velocity, $X_{T}^{*}=2.38$; (C) corresponding PEC values for various tube spacings, $\varepsilon=0.913$. The open symbols represent theoretical cases where $\mathrm{R}_{\text {bond }}$ was reduced by using Al-Si brazing. 
Table 1 Geometric properties of the aluminum foams used in this study.

\begin{tabular}{|c|c|c|c|c|c|c|}
\hline & $\varepsilon$ & ppi & $\mathrm{d}_{\mathrm{p}}[\mathrm{mm}]$ & $\mathrm{d}_{\mathrm{c}}[\mathrm{mm}]$ & $\mathrm{d}_{\mathrm{f}}[\mu \mathrm{m}]$ & $\mathrm{SA}\left[\mathrm{m}^{2} / \mathrm{m}^{3}\right]$ \\
\hline Foam 1 & $0.913 \pm 0.5$ & 20 & $2.45 \pm 0.03$ & $3.15 \pm 0.04$ & $310 \pm 50$ & $720 \pm 9 \%$ \\
\hline Foam 2 & $0.932 \pm 0.5$ & 10 & $4 \pm 0.06$ & $5.28 \pm 0.06$ & $460 \pm 50$ & $410 \pm 9 \%$ \\
\hline Foam 3 & $0.951 \pm 0.5$ & 10 & $4.1 \pm 0.07$ & $5.4 \pm 0.1$ & $400 \pm 50$ & $380 \pm 9 \%$ \\
\hline Foam 4 & $0.937 \pm 0.5$ & 20 & $2.7 \pm 0.03$ & $3.46 \pm 0.04$ & $280 \pm 50$ & $675 \pm 9 \%$ \\
\hline
\end{tabular}


Table 2. Curve fit coefficients to the plain tube data sets for the exterior heat transfer resistance and the pressure drop.

\begin{tabular}{|c|c|c|c|c|}
\hline$X_{T}^{*}$ & $\mathbf{a}$ & $\mathbf{b}$ & $\mathbf{c}$ & $\mathbf{d}$ \\
\hline 2.38 & 8.141 & -0.5592 & 0.6128 & 0.5097 \\
\hline 2.68 & 9.431 & -0.5672 & 0.4645 & 0.3249 \\
\hline 3.06 & 9.397 & -0.5439 & 0.4254 & 0.4423 \\
\hline 3.57 & 14.112 & -0.5773 & 0.3005 & 0.2695 \\
\hline
\end{tabular}

